\title{
Alantolactone Exhibits Antiproliferative and Apoptosis-Promoting Properties in Colon Cancer Model via Activation of the MAPK-JNK/c-Jun Signaling Pathway
}

\section{Cheng LV}

Shanghai University of Traditional Chinese Medicine Institute of Chinese Materia Medica https://orcid.org/0000-0002-0952-0323

\section{Yijing Ren}

Shanghai University of Traditional Chinese Medicine Jing Zhang

Shanghai University of Traditional Chinese Medicine

\section{Beibei Zhang}

Shanghai University of Traditional Chinese Medicine

Bei Yue

Shanghai University of Traditional Chinese Medicine

Xiaoping Luo

the Affiliated Hospital of Zunyi Medical University

\section{Zhilun Yu}

Shanghai University of Traditional Chinese Medicine

\section{Hao Wang}

Shanghai University of Traditional Chinese Medicine

\section{Junyu Ren}

Shanghai University of Traditional Chinese Medicine

Zhengtao Wang ( $\nabla$ ztwang@shutcm.edu.cn )

Shanghai University of Traditional Chinese Medicine

Wei Dou

Shanghai University of Traditional Chinese Medicine

\section{Research Article}

Keywords: MAPK-JNK/c-Jun, Proliferation, Apoptosis, Alantolactone

Posted Date: April 23rd, 2021 
DOl: https://doi.org/10.21203/rs.3.rs-432058/v1

License: (c) (1) This work is licensed under a Creative Commons Attribution 4.0 International License. Read Full License 


\section{Abstract}

Colorectal cancer (CRC) is one of the most common human malignancies in the digestive tract with high mortality. Alantolactone (ATL), as a plant-derived sesquiterpene lactone, has shown a variety of pharmacological activities, such as antibacterial, anti-inflammatory, anti-virus and so on. However, the exact molecular mechanism of ATL in colorectal cancer remains largely unknown. Here, we performed a study to explore the effect and mechanism of ATL on colorectal cancer. The CCK-8 assay, colony formation assay, Wound-healing and Transwell assays were performed to evaluate the cytotoxic effect, antiproliferative effect, anti-migratory and anti-invasive properties of ATL respectively. The xenograft tumor model was established in Balb/c mice to evaluate the anti-tumor effect. The expression levels of proteins involved the MAPK-JNK/c-Jun signaling pathway were measured by Western blot and RT-qPCR both in cells and tumor tissues. The results showed that ATL could inhibit the cells activities of various colon cancer cell lines. Moreover, ATL could induce HCT-116 cells nuclear pyknosis, mitochondrial membrane potential loss, G0/G1 phase arrest, as well as enhance the proportion of apoptosis cells and inhibit colony formation. The migration distance and invasion rate of cells were significantly reduced after treated with ATL. Additionally, in the xenograft model, ATL $(50 \mathrm{mg} / \mathrm{kg})$ significantly decreased the tumor tumor volume and weight ( $\mathrm{p} \otimes$ 0.001). For the anti-colon cancer mechanism, the ATL showed the anti-proliferative and pro-apoptosis effect by activating MAPK-JNK/C-Jun signaling pathway. In conclusion, ATL exhibits anti-proliferation and apoptosis-promoting potential in colon cancer via the activation of MAPK-JNK/c-Jun signaling pathway.

\section{Introduction}

The latest global cancer statistics released by the World Health Organization (WHO) indicate that colorectal cancer (CRC) is one of the most common malignant tumors worldwide, and the fourth leading cause of cancer-related mortality, with approximately 900,000 deaths reported every year[1]. Moreover, the incidence of CRC has increased rapidly in recent years, especially in developing countries in Africa and Central America, as well as in China [2]. CRC not only threatens human health, but also causes heavy losses to the global economy. By 2020, the medical care expenditure due to CRC in America has been estimated to reach $\$ 17$ billion [3].

The known etiological factors of CRC include diet, underlying diseases, genetics, and age. However, the exact pathogenic mechanisms underlying CRC remain unclear [4]. Clinical first-line therapeutic strategies for CRC are all "aggressive", including surgical resection, radiotherapy, and chemotherapy, all of which elicit only temporary effects, and the overall survival rates of CRC patients remain low [5]. Accumulating evidence has indicated that abnormal signaling related to various pathways is involved in the pathology of $\mathrm{CRC}$, such as cell proliferation, invasion, and metastasis [6]. The mitogen-activated protein kinase (MAPK) signaling pathway transforms extracellular stimuli into multiple cellular responses that affect tumorigenic processes, including cell proliferation, metabolism, apoptosis, and differentiation [7]. Therefore, targeting the MAPK pathway constitutes a promising strategy for CRC prevention and therapy [8]. Numerous studies have revealed that adjuvant chemotherapeutic herbal medicines can inhibit the 
proliferation and invasion of cancer cells, prevent recurrence and metastasis, improve the quality of life, and prolong the survival of CRC patients via regulation of the MAPK pathway [9]. Moreover, some herbal compounds, such as quercetin, epigallocatechin-3-gallate, resveratrol, and sulforaphene, are reported to exert anticancer effects by stimulating the MAPK pathway, thereby inducing apoptosis and inhibiting proliferation [10].

Alantolactone (ATL), a sesquiterpene compound, is primarily found in Inula helenium $L$, a medicinal plant with antiviral, antibacterial, and antitumorigenic properties[11]. Recent studies have shown that ATL exhibits a variety of pharmacological activities, prominent among which is its antitumorigenic effect against a wide range of cancer types, such as lung cancer, breast cancer, cervical cancer, myeloma, glioblastoma, and colorectal cancer[12]. The underlying mechanisms include inducing G1 phase arrest and oxidative DNA damage, as well as the promotion of apoptosis and mitochondrial dysfunction[12, 13]. However, the molecular mechanisms underlying the effects of ATL in CRC require further investigation.

In this study, we investigated the anti-CRC activity of ATL in various CRC cell lines and xenograft tumor model, and found that ATL exerts its antiproliferative and proapoptotic effects, at least partly, via the activation of the MAPK-JNK/c-Jun signaling pathway.

\section{Materials And Methods}

\section{Materials and reagents}

Alantolactone (purity $\geq 98 \%$ [HPLC], CAS:546-43-0) was purchased from Chengdu Biopurify Phytochemicals Ltd (China). SP600125 (an inhibitor of c-Jun N-terminal kinase [JNK]), PD98059 (an inhibitor of extracellular-regulated protein kinase [ERK]), and SB203580 (an inhibitor of p38 MAPK) were purchased from MedChemExpress (Monmouth Junction, NJ, USA). Propidium iodide (PI) and annexin V/PI were purchased from BD Pharmingen (San Diego, CA, USA). Transwell plates and Matrigel were purchased from Corning Incorporated (Corning, NY, USA). Cell Counting Kit-8 (CCK-8) was purchased from Dojindo (Kumamoto, Japan). Primary antibodies against cleaved caspase-3 (\#9661S), caspase-3 (\#9662S), cyclin-B1 (\#4138S), cyclin-E (\#4129S), cyclin-dependent kinase 4 (CDK4) (\#12790), JNK1/2 (\#9255), p-JNK1/2 (\#9252), p38 (\#9212), p-p38 (\#9215), ERK1/2 (\#4348), p-ERK1/2 (\#4377), and $\beta$-actin (\#4970) were supplied by Cell Signaling Technology (CST, Danvers, MA, USA). p21 (\#A16633), p53 (\#A3185), c-Jun (\#A11378), p-c-Jun (\#AP0048), and secondary goat anti-rabbit (\#AS014) or rabbit antimouse (\#AS003) antibodies were supplied by Abclonal (Wuhan, China). Anti-Bcl-2 (\#ab196495) and antiBAX (\#ab53154) antibodies were obtained from Abcam (Cambridge, MA, USA).

\section{Cell culture}

The human CRC cell lines (LS174T, HT29, SW480, SW620, HCT116, and CT26) were obtained from the American Type Culture Collection (Manassas, VA, USA). CT26 cells were cultured in 1640 medium supplemented with $10 \%$ FBS and a $1 \%$ P/S solution. LS174T cells were cultured in Dulbecco's modified Eagle's medium (DMEM) containing 10\% ( $/ / V)$ fetal bovine serum (FBS; Gibco, Waltham, MA, USA) and a 
1\% (v/v) penicillin-streptomycin (P/S) solution (Gibco). HCT116 and HT29 cells were cultured in McCoy's $5 \mathrm{~A}$ medium supplemented with $10 \% \mathrm{FBS}$ and a $1 \% \mathrm{P} / \mathrm{S}$ solution. SW480 and SW620 cells were cultured in Leibovitz's L-15 medium supplemented with $10 \%$ FBS and a 1\% P/S solution. All the cells were cultured at $37^{\circ} \mathrm{C}$ in a humidified atmosphere with $5 \% \mathrm{CO}_{2}$.

\section{Cell viability assay}

Cells $\left(1.5 \times 10^{4} /\right.$ well) were seeded into 96 -well plates and treated with different concentrations of ATL (0$100 \mu \mathrm{M})$ for $24 \mathrm{~h}$. Subsequently, the cells were incubated with a $10 \% \mathrm{CCK}-8$ solution at $37^{\circ} \mathrm{C}$ for $0.5 \mathrm{~h}$. Cell viability was assessed by determination of the optical density (OD) at $450 \mathrm{~nm}$ using Varioskan Flash (Thermo Fisher Scientific, Waltham, MA, USA) following the manufacturer's instructions, and results were presented as means $\pm \mathrm{SD}$.

\section{Wound-healing assay}

HCT 116 cells were seeded into a 6 -well plate at a density of $1 \times 10^{5}$ cells $/ \mathrm{mL}$. When the cells had reached 80-90\% confluence, a scratch was made with a sterile pipette. Following washing, floating cells were removed and serum-free medium was added. The cells were treated with $2.5,5$, or $10 \mu \mathrm{M}$ ATL for $24 \mathrm{~h}$. At $0 \mathrm{~h}$ and $24 \mathrm{~h}$, the scratch width was observed and recorded under an inverted microscope. The percent wound closure was determined using ImageJ software. At least three randomly selected areas were assayed for each well.

\section{Transwell chamber invasion assay}

Cell invasion assays were conducted using Matrigel-coated transwell chambers. FBS medium (20\%) was added to the lower chamber, and $2 \times 10^{5} \mathrm{HCT} 116$ cells were plated onto the upper chambers and incubated with $2.5,5$, or $10 \mu \mathrm{M}$ ATL. After $24 \mathrm{~h}$, noninvading cells were removed, and the remaining cells stained with crystal violet. Subsequently, invading cells were fixed, stained, visualized, and counted. The assays were performed in triplicate. Cell invasion rate was determined as (\%) $=[O D$ (administration) $-O D$ (blank)]/[OD (control) - OD (blank)] × 100\%.

\section{Colony formation assay}

HCT116 cells were seeded into 6-well plates at a density of 1000 cells/well and exposed to $2.5,5$, or 10 $\mu \mathrm{M}$ ATL. The medium was replaced every 2 days. The cells were cultured for 8 days until colonies formed. Then, the cells were fixed in $4 \%$ paraformaldehyde for $15 \mathrm{~min}$ and stained with $0.01 \%$ crystal violet for 10 min at room temperature. Colony formation rate was determined as $(\%)=[O D$ (administration) - OD (blank)]/[OD (control) - OD (blank)] × 100\%.

\section{Flow cytometry analysis of cell cycle and apoptosis}

HCT116 cells were treated with or without $7.5,15$, or $30 \mu \mathrm{M}$ ATL for $24 \mathrm{~h}$ and subsequently harvested (at least $1 \times 10^{6}$ cells per group). Cells were harvested separately and immediately fixed in $75 \%$ ice-cold ethanol. For analysis of cell cycle progression, cells were stained with PI staining buffer $(10 \mathrm{mg} / \mathrm{mL} \mathrm{PI}$ and $100 \mathrm{mg} / \mathrm{mL}$ RNase A) for $30 \mathrm{~min}$, and fluorescence intensity was measured in a Guava easyCyte 
6HT-2 system (Millipore, MA, USA). Modfit analysis software was used to determine the percentage of cells in the different phases of the cell cycle. For apoptosis analysis, $5 \mu \mathrm{L}$ of annexin V-FITC and $5 \mu \mathrm{L}$ of PI were added to the cells. After incubation at room temperature for $15 \mathrm{~min}$ in the dark, the cells were detected using Guava easyCyte 6HT-2 (excitation, $488 \mathrm{~nm}$; emission, $530 \mathrm{~nm}$ ) and then analyzed using Flowjo software.

\section{Hoechst 33258 fluorescence staining}

HCT 116 cells were seeded on sterile circular coverslips in a 24-well plate at a density of $4 \times 10^{5}$ cells/well and then incubated with or without ATL $(7.5,15$, or $30 \mu \mathrm{M})$ for $24 \mathrm{~h}$. The cells were washed twice with PBS, fixed in $4 \%$ formaldehyde for $15 \mathrm{~min}$, and washed again with PBS. The cells were then stained with Hoechst $33258(10 \mu \mathrm{g} / \mathrm{mL})$ for $15 \mathrm{~min}$ and rinsed with PBS. Images were obtained using a fluorescence microscope (Olympus, Center Valley, PA, USA).

\section{JC-1 fluorescence staining}

HCT 116 cells $\left(2 \times 10^{5}\right.$ cells/well) were seeded in 6-well plates. After $12 \mathrm{~h}$ of incubation, the cells were treated with ATL $(30 \mu \mathrm{M})$ for $24 \mathrm{~h}$, and then incubated with the $\mathrm{JC}-1$ probe $(2 \mu \mathrm{g} / \mathrm{mL})$ at $37^{\circ} \mathrm{C}$ for $10 \mathrm{~min}$. Finally, images were captured using a fluorescence microscope (Olympus CKX41, Tokyo, Japan).

\section{Immunoblotting analysis}

Cultured HCT116 cells were homogenized in lysis buffer containing protease and phosphatase inhibitor cocktail tablets (Roche Diagnostics $\mathrm{GmbH}$, Mannheim, Germany). The supernatant was collected after centrifugation $\left(4^{\circ} \mathrm{C}, 12,000 \times \mathrm{g}, 15 \mathrm{~min}\right)$. Proteins $(30 \mu \mathrm{g})$ were separated by $10 \%$ SDS-PAGE and transferred onto a PVDF membrane. The membrane was blocked in $5 \%(\mathrm{w} / \mathrm{v})$ skimmed milk for $2 \mathrm{~h}$ at room temperature and immunoblotted with primary antibodies. The blots were then washed and incubated with HRP-conjugated secondary antibody at room temperature. Finally, the blots were observed using enhanced chemiluminescence (ECL) reagents. Protein expression was analyzed using a GS-700 imaging densitometer (Bio-Rad, Hercules, CA, USA). $\beta$-actin was used as an internal control.

\section{Cell transfection}

The human JNK expression plasmid pRP-EGFP-hMAPK8 (pRP[Exp]-EGFP/Puro-CAG > hMAPK8[NM_001278547.1]) was purchased from vector builder (Guangzhou, China). The pRP-EGFP-

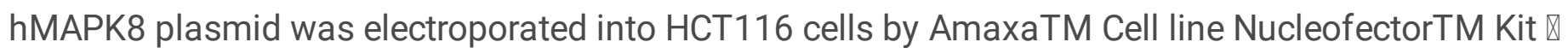
(Basel, Switzerland) as previously described [14].

\section{In vivo antitumor study and immunohistochemistry}

Healthy six-week-old BALB/c mice were purchased from the Shanghai Laboratory Animal Center. All animals were handled according to the principles of the declaration recommendations of the Animal Experimentation Ethics Committee at Shanghai University of Traditional Chinese Medicine (Animal license key:PZSHUTCM18122106). CT26 colon cancer cells ( $1 \times 10^{6}$ in $100 \mu \mathrm{L}$ of PBS) were harvested and subcutaneously injected into the right flank of mice. Three days afterwards, all the tumor-bearing animals 
were divided into the following groups ( $\mathrm{n}=6$ mice per group), control group, and two alantolactonetreated groups (dosage $25 \mathrm{mg} / \mathrm{kg}$ and $50 \mathrm{mg} / \mathrm{kg}$ ). Alantolactone was dissolved in vehicle solution ( $1 \%$ DMSO + 2\% Tween $80+97 \%$ saline) and administered by intraperitoneal injectiononce once a day. At the end of experiment, all the mice were euthanized under anesthesia and the tumors were removed and weighted. Tumor volume was determined by measuring length $(\mathrm{L}, \mathrm{mm})$ and width $(\mathrm{W}, \mathrm{mm})$ to calculate volume $\left(\mathrm{V}=0.5 \times \mathrm{L} \times \mathrm{W}^{2}\right)$.

The harvested tumors were fixed in $4 \%$ paraformaldehyde for $24 \mathrm{~h}$. Subsequently, tumor tissues were embedded in paraffin and cut into $5 \mu \mathrm{m}$ sections. Tissue sections were incubated with antibodies against PCNA (1:8000 dilution, \#13110), CyclinD1 (1:50 dilution, \#2978), p-JNK (1:50 dilution, \#4688), and p-cJun (1:50 dilution, \#3270). All the primary antibodies were purchased from Cell signaling Technology (CST, Danvers, MA, USA). The signal was dectected by the HRP-Goat-antiRabbit secondary antibody, and colour was labeled by 3,3'-diaminobenzidine (DAB).

\section{Statistical methods}

Comparisons between multiple groups were performed using one-way analysis of variance (ANOVA) in GraphPad Prism 7 (GraphPad Software, La Jolla, CA, USA). Data were presented as means \pm SD. $p$-values $<0.05$ (two-sided) were considered significant $\left({ }^{\star} p<0.05,{ }^{\star \star} p<0.01,{ }^{\star \star \star} p<0.001\right)$.

\section{Results}

\section{ATL impaired the viability of different CRC cell types}

CCK-8 was used to detect the concentration-dependent cytotoxic effects of ATL in SW480, SW620, HT29, LS174T, and HCT116 CRC cells. The results showed that ATL suppressed the viability of these cells (Fig. 1). The $50 \%$ inhibitory concentration ( $\mathrm{IC}_{50}$ ) was (from low to high) $11.84 \mu \mathrm{M}$ for HCT116 cells, 12.86 $\mu \mathrm{M}$ for SW620 cells, $17.9 \mu \mathrm{M}$ for SW480 cells, $22.22 \mu \mathrm{M}$ for LS174T cells, and 33.97 $\mu \mathrm{M}$ for HT-29 cells. As HCT116 cells showed the lowest $\mathrm{IC}_{50}$, they were selected for subsequent experiments.

\section{ATL suppressed the proliferation of CRC cells}

A cell viability assay was performed to confirm the suppressive effects of ATL on HCT116 cells under different concentrations and at different time points. The results showed that ATL treatment decreased the viability of HCT116 cells in a dose- and time-dependent manner (Fig. 2A). To further explore the repressive effect of ATL on HCT116 cells, a colony formation assay was performed to determine cell proliferation. Crystal violet staining results showed that ATL significantly suppressed $(p<0.001)$ HCT116 cell colony number and size in a dose-dependent manner after 7 days of low-density cell culture when compared with control cells (Fig. 2B, left panel). This indicated that ATL can inhibit the proliferation of CRC cells.

\section{ATL induced G0/G1 phase arrest in CRC cells}


To further evaluate the inhibitory effects of ATL, flow cytometry was applied to measure the cell cycle distribution of HCT116 cells following ATL treatment. Compared with the control group, the proportion of cells in the G0/G1 phase was significantly increased in ATL-treated cells, whereas the proportion of cells in the $S$ and G2/M phases was decreased (Fig. 3A). The cell cycle is precisely regulated through the activity of specific proteins, including p21, cyclin-B1, cyclin-D1, and cyclin-E. p21 functions as a tumor suppressor, and is involved in the regulation of cell proliferation by inhibiting the CDK complex. Cyclin-B1, cyclin-D1, and cyclin-E play crucial rate-limiting roles for entry into mitosis. Accumulation of cyclin-E at the $\mathrm{G} 1 / \mathrm{S}$ transitional period accelerates cell entry into the $S$ phase. We therefore analyzed the protein levels of p21, cyclin-B1, cyclin-D1, cyclin-E, and CDK4 in HCT116 cells by immunoblotting. The results showed that ATL treatment increased the protein level of p21 in a time- and concentration-dependent manner (Fig. 3B), while decreasing those of cyclin-B1, cyclin-D1, cyclin-E, and CDK4, also in a time- and concentration-dependent manner.

\section{ATL induced apoptosis in CRC cells}

Hoechst staining was performed to evaluate the morphological changes occurring in the nucleus of ATLtreated cells. The chromatin of HCT116 cells was evenly distributed in control cells, whereas chromatin condensation increased with increasing concentrations of ATL, indicative of an increase in cell apoptosis (Fig. 4A). Subsequently, annexin V-FITC/PI double staining and flow cytometry were used to verify the apoptosis-inducing effects of ATL. The first, second, third, and fourth quadrants represent the proportion of cells in the late apoptotic stage, those with mechanical injury, nonapoptotic cells, and early apoptotic cells, respectively. In short, the sum of the first and fourth quadrants is the proportion of total apoptotic cells. As shown in Fig. 4B, the percentages of apoptotic cells induced by ATL at $0,7.5,15$, and $30 \mu \mathrm{M}$ were $20.71 \pm 2.17 \%, 55.00 \pm 5.14 \%, 65.86 \pm 4.75 \%$, and $68.33 \pm 2.47 \%$, respectively $(p<0.001)$. To further explore the mechanisms involved in ATL-induced apoptosis, we examined the levels of apoptosis-related proteins by immunoblot assay. Similar to the results for the Hoechst staining and annexin V-FITC/PI double-staining assays, the expression levels of cleaved caspase- 3 and proapoptotic BAX were upregulated, whereas that of antiapoptotic Bcl-2 was downregulated in a dose- and time-dependent manner (Fig. 5A). These results indicated that ATL promoted the apoptosis of HCT116 cells.

\section{ATL treatment led to the loss of mitochondrial transmembrane potential in CRC cells}

Disruption of mitochondrial transmembrane potential is closely related to cell apoptosis [15]. Maintaining a high mitochondrial membrane potential is beneficial for metabolic homeostasis, including inhibition of cell apoptosis [16]. JC-1 dye is a fluorescent probe commonly used to assess changes in the mitochondrial membrane potential, with a greater proportion of JC-1 monomers (green) indicating a lower mitochondrial membrane potential [17]. JC-1 staining results showed that ATL treatment increased the percentage of JC-1 monomers (Fig. 5B), indicating that the mitochondrial membrane potential was disrupted. 


\section{ATL suppressed the migratory and invasive abilities of CRC cells}

The wound-healing assay is a method commonly used to detect the migratory ability of cancer cells. In the scratch-wound model, ATL treatment decreased the migratory distance of the HCT116 cells in a dosedependent manner (Fig. 6A). Additionally, a Transwell invasion assay was performed to examine the invasive ability of cancer cells. The results showed that, compared with controls, the number of migrated cancer cells was significantly reduced following ATL treatment (Fig. 6B).

\section{ATL treatment activated the MAPK-JNK/c-Jun signaling pathway}

Activation of the MAPK signaling pathway has been indicated to repress proliferation and accelerate apoptosis [18]. Consequently, we assessed the levels of key proteins in the MAPK pathway. As shown in Fig. 7A and $B$, the expression levels of p-JNK1/2, p-p38, and p-ERK1/2 were significantly enhanced in ATL-treated cells in a dose- and time-dependent manner $(p<0.05)$, with $p$-JNK1/2 expression showing the greatest increase. Because JNK phosphorylates cJun, leading to increased expression of proapoptotic genes, we next determined the effects of ATL administration on cJun phosphorylation/activation. The results showed that the phosphorylation level of C-Jun was significantly enhanced in HCT116 cells following ATL treatment (Fig. 8A).

To verify whether ATL exerts its anticancer activity by activating the MAPK pathway, we pretreated HCT116 cells with various MAPK inhibitors for $2 \mathrm{~h}$ before ATL treatment. As shown in Fig. 8B, ATL treatment significantly suppressed the viability of HCT116 cells, while co-treatment with the JNK inhibitor SP600125 suppressed the anticancer effect of ATL $(p<0.001)$. Compared with the JNK inhibitor SP600125, treatment with the p38 inhibitor SB203580 or ERK inhibitor PD98059 did not significantly suppress the ATL-mediated anticancer effects when compared with SP600125 (Fig. 8B). To further confirm whether the activation of JNK pathway mediated the anticancer effect of ATL, we transfected the human JNK expression plasmid pRP-EGFP-hMAPK8 into SP600125 pretreated HCT116 cells. Results of imaging by fluorescence microscope demonstrated that the transferring of pRP-EGFP-hMAPK8 plasmid was successful (Fig. 8C). We found that JNK inhibitor SP600125 was unable to rescue the inhibitory effect of ATL in pRP-EGFP-hMAPK8 transfected HCT116 cells (Fig. 8C), indicating that JNK is required for ATL-mediated suppression of HCT116 cell viability.

\section{ATL treatment inhibited colon tumor growth via activating MAPK-JNK/c-Jun signal pathway in vivo}

To validate the potential anti-tumor effect of ATL in vivo, tumor-bearing models were established by subcutaneously implanting CT26 colon cancer cells to mice. Subsequently, the anti-tumor effect of ATL was evaluated. As shown in Fig. 9A and 9D, $50 \mathrm{mg} / \mathrm{kg}$ ATL treatment significantly restrained the tumor growth in mice, no matter in the tumor volume or weight $(p<0.001)$ compared with the vehicle treated 
control. Similar results were observed in daily changes of tumor volume compared with the control group. As shown in Fig. 9C, starting from the day 12 ATL treatment significantly inhibited the tumor growth ( $p<$ 0.001). However, all ATL treatments did not affect the overall body weight throughout the whole 16 days duration of the experiment, indicating no obvious toxicity of ATL administration (Fig. 9C).

We additionally confirmed the tumor-suppression effect of ATL was relvant to the activation of MAPKJNK/c-Jun signal pathway. ATL treatmeht $(50 \mathrm{mg} / \mathrm{kg}$ ) significantly decreased the expression of PCNA ( $p$ $<0.001$ ) in the tumor tissues (Fig. 10A). Immunohistochemical studies demonstrated that the levels of $p$ JNK and p-c-Jun were higher, and CyclinD1 was lower in the ATL treated mice compared with the control mice (Fig. 10C and D). Furthermore, the western blot results (Fig. 10E and F) were consistent with the aforementioned results, which indicates a good accordance with the in vitro study. Taken together, these results indicated that activating MAPK-JNK/c-Jun signal pathway was involved in the tumor suppressive effect of ATL.

\section{Discussion}

Colorectal cancer, a serious life-threatening disease, is associated with a variety of endogenous and exogenous pathogenic factors, including obesity, underlying disease, lack of physical exercise, heredity, age, environment, and diet [1]. Several natural herbs have been reported to enhance the sensitivity of chemotherapeutic drugs (platinum salt, taxanes, and bortezomib) in CRC patients [19]. Despite the improvements in treatment approaches, the prognosis for CRC patients remains poor. Hence, new therapeutic drugs must be identified for use in the treatment of CRC.

In this study, we observed that ATL suppressed the viability of various human CRC cell lines. Colony formation assays confirmed the antiproliferative effects of ATL on CRC cells. Cell proliferation can be divided into five stages: a quiescent phase (G0), growth phase (G1), DNA replication phase (S phase), anaphase (G2), and mitosis ( $\mathrm{M}$ phase). Moreover, different cyclin proteins are involved in the regulation of cell proliferation at different stages[20]. Our results showed that ATL treatment induced G0/G1 phase arrest and suppressed the levels of cell cycle-related proteins, including p21, cyclin-B1, cyclin-D1, cyclin-E, and CDK4 in CRC cells.

Programmed cell death primarily occurs via apoptosis mediated by the activation of caspase proteins. Apoptosis is an extremely complicated, precisely regulated, protease-dependent molecular cascade [21] characterized mainly by the aggregation of chromatin in the nucleus [22]. Our studies confirmed that chromatin condensation occurred with ATL treatment. Subsequent flow cytometry analysis confirmed the proapoptotic effects of ATL. Bcl-2 and BAX are two critical regulators of the mitochondrial apoptotic pathway. As expected, we observed a reduction in the mitochondrial transmembrane potential, as well as a downregulation of apoptosis-related proteins, including cleaved caspase-3, BAX, and Bcl-2, following ATL treatment. Besides the antiproliferative and proapoptotic effects, we also found that ATL could reduce the migratory and invasive abilities of CRC cells in a dose-dependent manner, without affecting cell viability. 
MAPK signaling serves as an important signal transduction pathway in tumor suppression and induction of apoptosis. Classical MAPKs include ERK1/2, JNK-1/2/3, and $p 38-\alpha / \beta / \gamma / \delta$, which are involved in cell cycle regulation and induction of cell apoptosis when activated [23]. We found that the phosphorylation levels of JNK1/2, p38, and ERK1/2 were upregulated with ATL treatment in a time- and dose-dependent manner, and the JNK1/2 was the most highly phosphorylated. C-Jun, a member of the activation protein 1 (AP-1) family, is the transcription factor of JNK1/2. Activated p-JNK can activate c-Jun and further promote c-Jun phosphorylation and translocation into the nucleus, thereby directly regulating the cell cycle and apoptosis [24]. We found that ATL treatment significantly enhanced the phosphorylation levels of JNK1/2 and c-Jun. Subsequent treatment with different MAPK inhibitors confirmed the regulatory role of JNK in the anticancer effects of ATL. Further experiments showed that the introduction of pRP-EGFPhMAPK8 plasmid prevented the rescue tendency of JNK inhibitor SP600125 in ATL treated HCT116 cells. Together these results indicate that ATL could inhibit cancer growth at least partially through targeting MAPK-JNK/c-Jun signaling pathway.

Collectively, the results of the current study indicated that ATL could induce the apoptosis of CRC cells, and inhibit their proliferative, migratory, and invasive abilities. Furthermore, ATL (50 mg/kg) administration significantly inhibited colon tumor growth in xenograft tumor. ATL may exert its anti-CRC effects via activating the MAPK-JNK/C-Jun signaling pathway, at least in part (Fig. 11). These findings highlight a potentially valuable application for ATL in treating CRC. However, further investigation, particularly animal and clinical studies, will be necessary to further confirm the potential for the application of ATL in CRC prevention and treatment.

\section{Declarations}

\section{Funding}

Financial support was provided by the National Natural Science Foundation of China (Grant Nos. 81920108033), Natural Science Foundation of Shanghai (Grant No. 20ZR1458000)

\section{Conflicts of interest}

The authors declare that there is no conflict of interest regarding the publication of the manuscript.

\section{Availability of data and material}

The data that support the findings of this study are available from the corresponding author upon reasonable request.

\section{Code availability}

Not applicable

\section{Authors' contributions}


Yijing Ren, Cheng Lv, Jing Zhang performed experiments. Beibei Zhang, Bei Yue, Xiaoping Luo analyzed the data. Zhilun Yu, Hao Wang drafted the manuscript. Junyu Ren edited and revised manuscript. Zhengtao Wang, Wei Dou participated in research design and approved final version of manuscript. All authors reviewed the manuscript.

\section{Ethics approval}

To work with mice samples, ethical approval (PZSHUTCM18122106) was obtained from the Animal Experimentation Ethics Committee at Shanghai University of Traditional Chinese Medicine.

\section{Consent to participate}

Not applicable

\section{Consent for publication}

Not applicable

\section{Compliance with ethical standards}

Conflict of interest:9 The authors declare that they have no actual or potential conflicts of interest.

\section{References}

1. Dekker E, Tanis PJ, Vleugels JLA, Kasi PM and Wallace MB (2019) Colorectal cancer. Lancet 394:1467-1480. doi: 10.1016/S0140-6736(19)32319-0

2. Chen W (2015) Cancer statistics: updated cancer burden in China. Chin J Cancer Res 27:1. doi: 10.3978/j.issn.1000-9604.2015.02.07

3. Bakr O, Afsar-Manesh N, Raja N, Dermenchyan A, Goldstein NJ, Shu SB and May FP (2020) Application of Behavioral Economics Principles Improves Participation in Mailed Outreach for Colorectal Cancer Screening. Clin Transl Gastroenterol 11:e00115. doi: $10.14309 / \mathrm{ctg} .0000000000000115$

4. Murphy N, Moreno V, Hughes DJ, Vodicka L, Vodicka P, Aglago EK, Gunter MJ and Jenab M (2019) Lifestyle and dietary environmental factors in colorectal cancer susceptibility. Mol Aspects Med 69:29. doi: 10.1016/j.mam.2019.06.005

5. Vogel JD, Eskicioglu C, Weiser MR, Feingold DL and Steele SR (2017) The American Society of Colon and Rectal Surgeons Clinical Practice Guidelines for the Treatment of Colon Cancer. Dis Colon Rectum 60:999-1017. doi: 10.1097/DCR.0000000000000926

6. Marmol I, Sanchez-de-Diego C, Pradilla Dieste A, Cerrada E and Rodriguez Yoldi MJ (2017) Colorectal Carcinoma: A General Overview and Future Perspectives in Colorectal Cancer. Int J Mol Sci 18. doi: 10.3390/ijms 18010197 
7. Koveitypour Z, Panahi F, Vakilian M, Peymani M, Seyed Forootan F, Nasr Esfahani MH and Ghaedi K (2019) Signaling pathways involved in colorectal cancer progression. Cell Biosci 9:97. doi: 10.1186/s13578-019-0361-4

8. Pancione M, Giordano G, Parcesepe P, Cerulo L, Coppola L, Curatolo AD, Conciatori F, Milella M and Porras A (2017) Emerging Insight into MAPK Inhibitors and Immunotherapy in Colorectal Cancer. Curr Med Chem 24:1383-1402. doi: 10.2174/0929867324666170227114356

9. Ge L, Wang YF, Tian JH, Mao L, Zhang J, Zhang JH, Shen XP and Yang KH (2016) Network metaanalysis of Chinese herb injections combined with FOLFOX chemotherapy in the treatment of advanced colorectal cancer. J Clin Pharm Ther 41:383-91. doi: 10.1111/jcpt.12410

10. Afrin S, Giampieri F, Gasparrini M, Forbes-Hernandez TY, Cianciosi D, Reboredo-Rodriguez P, Zhang J, Manna PP, Daglia M, Atanasov AG and Battino M (2020) Dietary phytochemicals in colorectal cancer prevention and treatment: A focus on the molecular mechanisms involved. Biotechnol Adv 38:107322. doi: 10.1016/j.biotechadv.2018.11.011

11. Zhao YM, Wang J, Liu HB, Guo CY and Zhang WM (2015) Microwave-assisted Extraction of Alantolactone and Isoalantolactone from Inula helenium. Indian J Pharm Sci 77:116-20. doi: 10.4103/0250-474x.151594

12. Yao Y, Xia D, Bian Y, Sun Y, Zhu F, Pan B, Niu M, Zhao K, Wu Q, Qiao J, Fu C, Li Z and Xu K (2015) Alantolactone induces $\mathrm{G} 1$ phase arrest and apoptosis of multiple myeloma cells and overcomes bortezomib resistance. Apoptosis 20:1122-33. doi: 10.1007/s10495-015-1140-2

13. Zhao P, Pan Z, Luo Y, Zhang L, Li X, Zhang G, Zhang Y, Cui R, Sun M and Zhang X (2015) Alantolactone Induces Apoptosis and Cell Cycle Arrest on Lung Squamous Cancer SK-MES-1 Cells. J Biochem Mol Toxicol 29:199-206. doi: 10.1002/jbt.21685

14. Yu Z, Yue B, Ding L, Luo X, Ren Y, Zhang J, Mani S, Wang Z and Dou W (2020) Activation of PXR by Alpinetin Contributes to Abrogate Chemically Induced Inflammatory Bowel Disease. Front Pharmacol 11:474. doi: 10.3389/fphar.2020.00474

15. Srinivasan S, Guha M, Kashina A and Avadhani NG (2017) Mitochondrial dysfunction and mitochondrial dynamics-The cancer connection. Biochim Biophys Acta Bioenerg 1858:602-614. doi: 10.1016/j.bbabio.2017.01.004

16. Hou XS, Wang HS, Mugaka BP, Yang GJ and Ding Y (2018) Mitochondria: promising organelle targets for cancer diagnosis and treatment. Biomater Sci 6:2786-2797. doi: 10.1039/c8bm00673c

17. Sivandzade F, Bhalerao A and Cucullo L (2019) Analysis of the Mitochondrial Membrane Potential Using the Cationic JC-1 Dye as a Sensitive Fluorescent Probe. Bio Protoc 9. doi: 10.21769/BioProtoc.3128

18. Peluso I, Yarla NS, Ambra R, Pastore G and Perry G (2019) MAPK signalling pathway in cancers: Olive products as cancer preventive and therapeutic agents. Semin Cancer Biol 56:185-195. doi: 10.1016/j.semcancer.2017.09.002

19. Chen D, Zhao J and Cong W (2018) Chinese Herbal Medicines Facilitate the Control of Chemotherapy-Induced Side Effects in Colorectal Cancer: Progress and Perspective. Front Pharmacol 
9:1442. doi: 10.3389/fphar.2018.01442

20. Jiang SX, Qi B, Yao WJ, Gu CW, Wei XF, Zhao Y, Liu YZ and Zhao BS (2017) Berberine displays antitumor activity in esophageal cancer cells in vitro. World J Gastroenterol 23:2511-2518. doi: 10.3748/wjg.v23.i14.2511

21. Elmore S (2007) Apoptosis: a review of programmed cell death. Toxicol Pathol 35:495-516. doi: 10.1080/01926230701320337

22. Rabbani A, Finn RM and Ausio J (2005) The anthracycline antibiotics: antitumor drugs that alter chromatin structure. Bioessays 27:50-6. doi: 10.1002/bies.20160

23. Yue J and Lopez JM (2020) Understanding MAPK Signaling Pathways in Apoptosis. Int J Mol Sci 21. doi: $10.3390 / \mathrm{ijms} 21072346$

24. Wu Q, Wu W, Jacevic V, Franca TCC, Wang X and Kuca K (2020) Selective inhibitors for JNK signalling: a potential targeted therapy in cancer. J Enzyme Inhib Med Chem 35:574-583. doi: $10.1080 / 14756366.2020 .1720013$

\section{Figures}



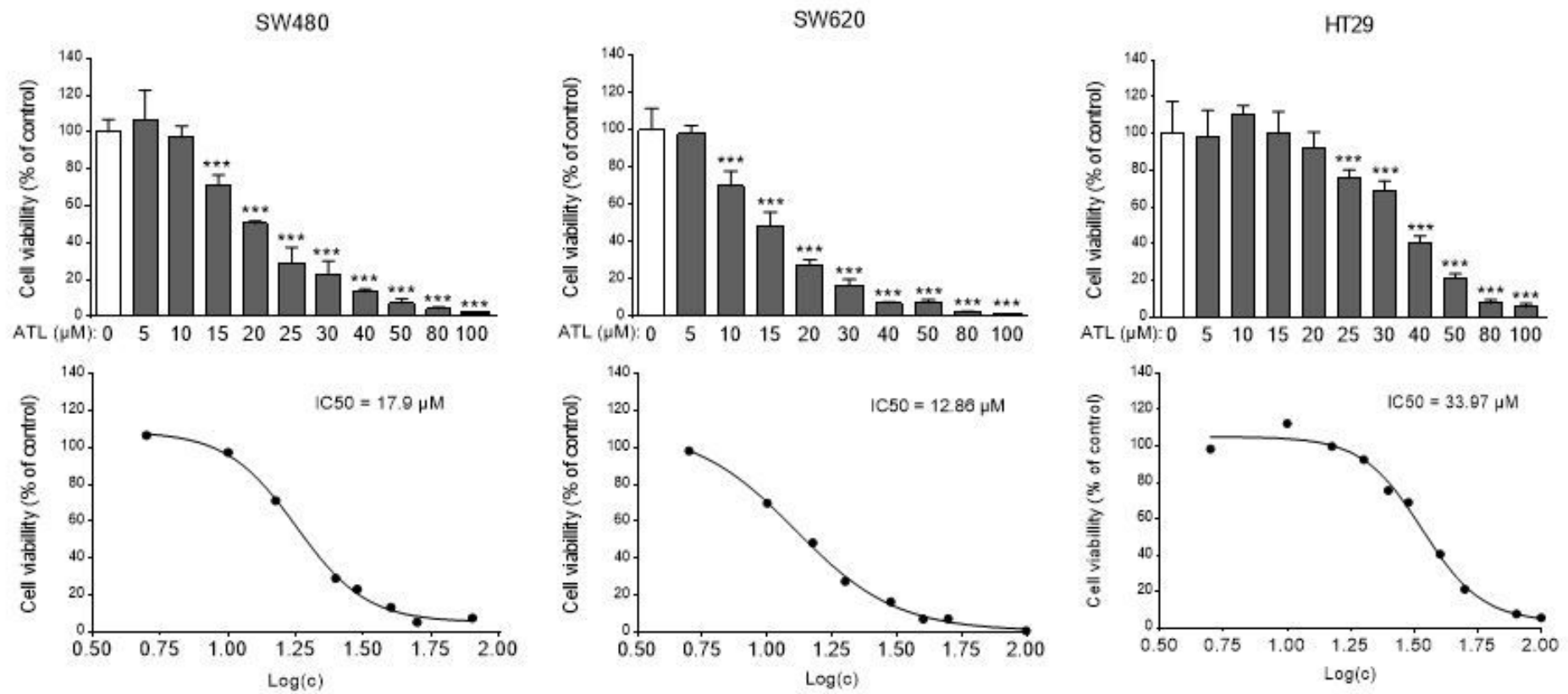

B
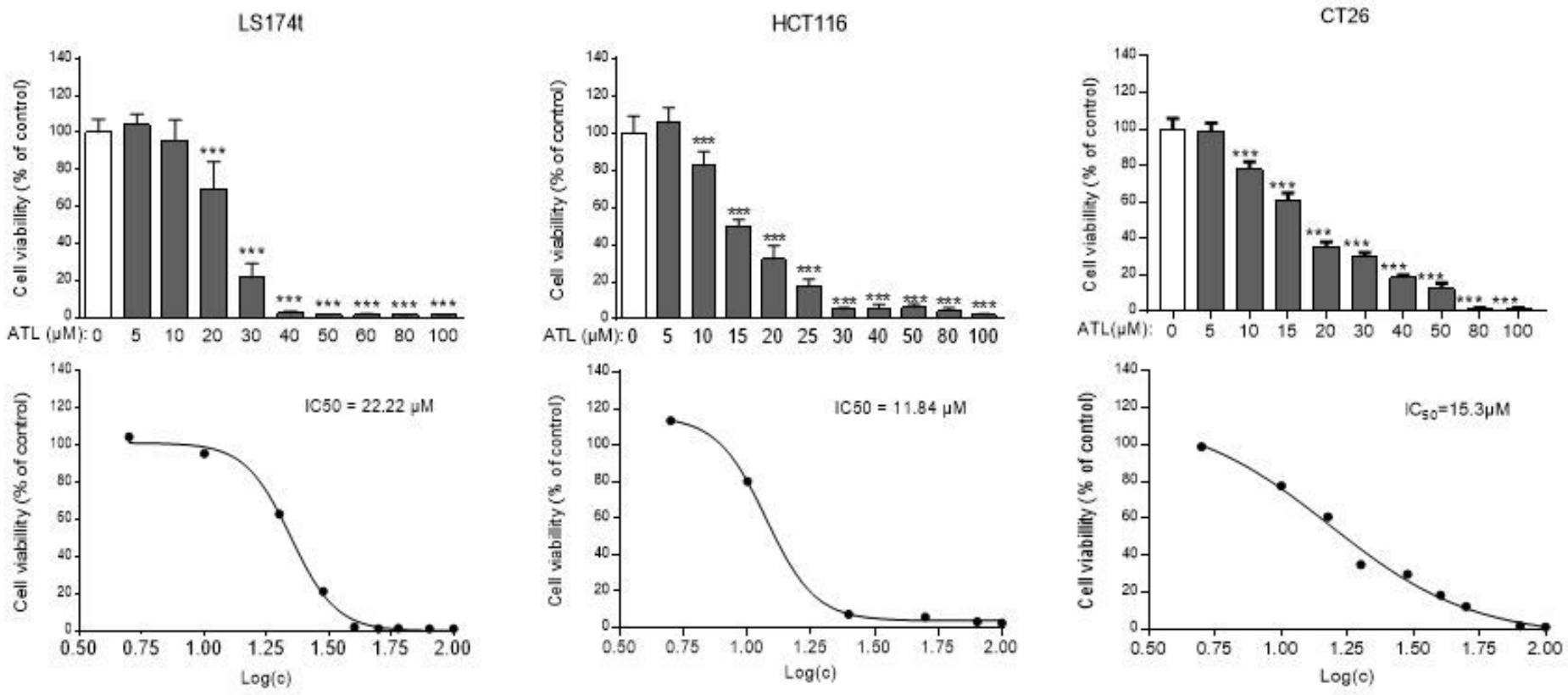

\section{Figure 1}

ATL inhibited the viability of CRC cells. (A, B) SW480, SW620, HT29, LS174t, HCT116 and CT26 cells were incubated with increasing doses of ATL $(5-100 \mu \mathrm{M})$ for $24 \mathrm{~h}$. The cytotoxic effect of ATL was measured by CCK-8 assay. Data are presented as means \pm SD $(n=6) .{ }^{\star} p<0.05,{ }^{\star \star} p<0.01$, ${ }^{\star \star \star} p<0.001$ vs. the $0-\mu M$ group. 
A

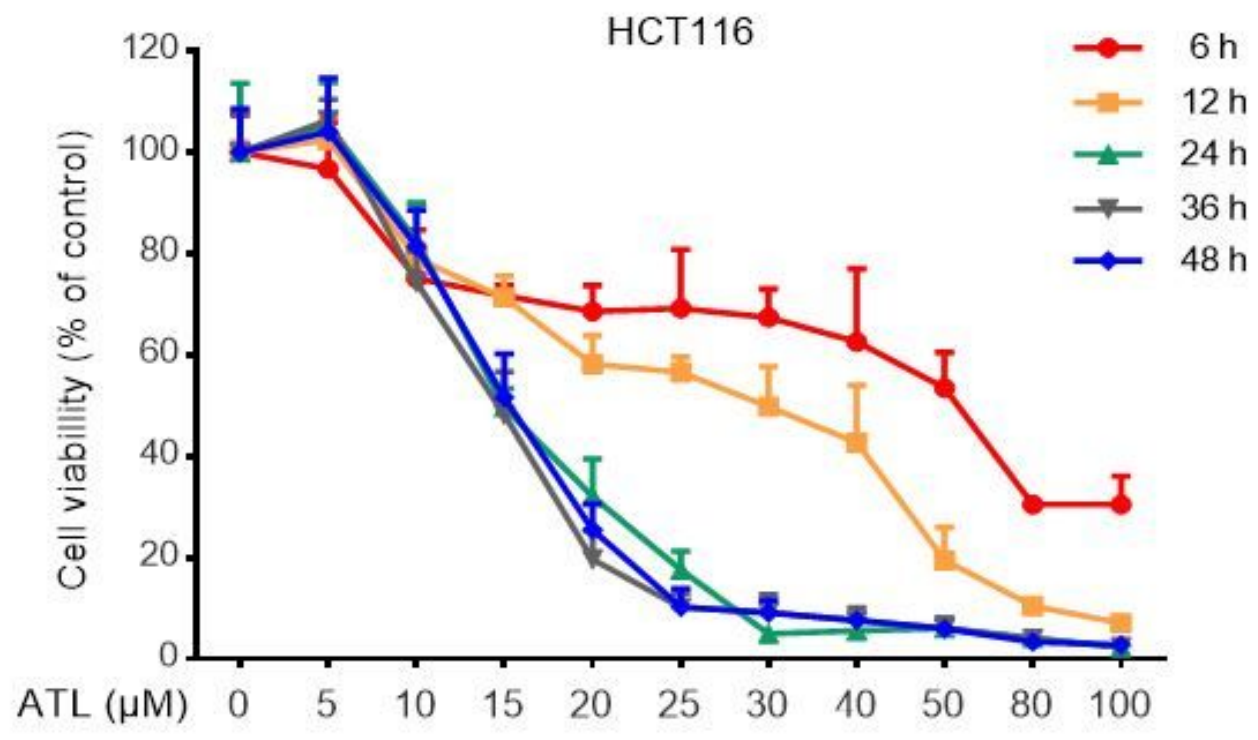

B

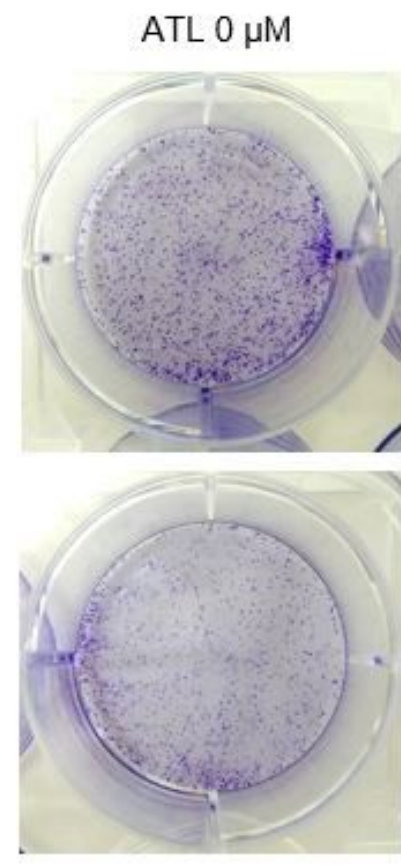

ATL $5 \mu \mathrm{M}$
ATL $2.5 \mu \mathrm{M}$

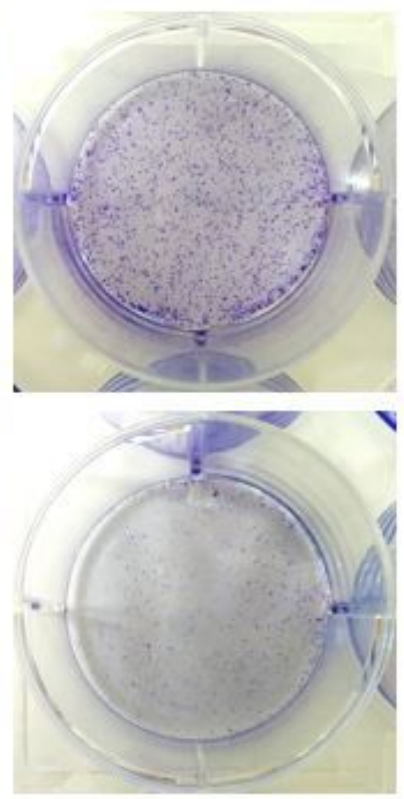

ATL $10 \mu \mathrm{M}$

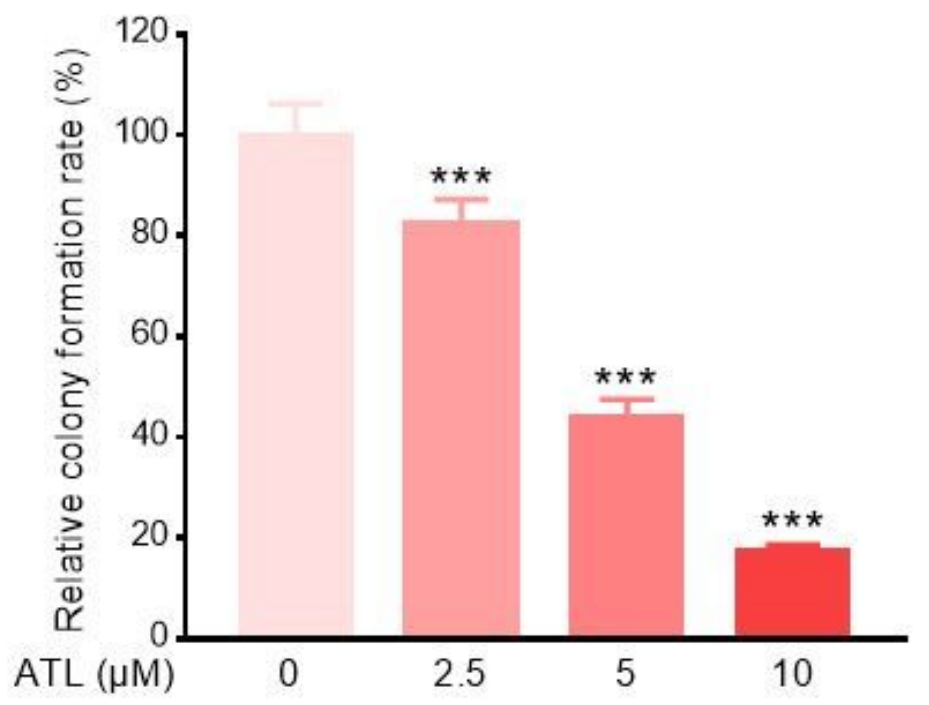

Figure 2

ATL inhibited colony formation in HCT116 cells. (A) HCT116 cells were incubated with increasing doses of ATL $(5-100 \mu \mathrm{M})$ for $6,12,24,36$, or $48 \mathrm{~h}$. The cytotoxic effect of ATL on HCT116 cells was measured by CCK-8 assay; the inhibition curves of ATL are shown. (B) HCT116 cells were treated with ATL $(2.5,5$, or $10 \mu \mathrm{M})$ for 7 days and then stained with crystal violet and imaged. The crystal violet was eluted with $70 \%$ ethanol, and the OD value was measured to evaluate the colony formation rate. Data are presented as means $\pm S D(n=3)$. ${ }^{* *} p<0.001$ vs. the $0-\mu M$ group. 
A
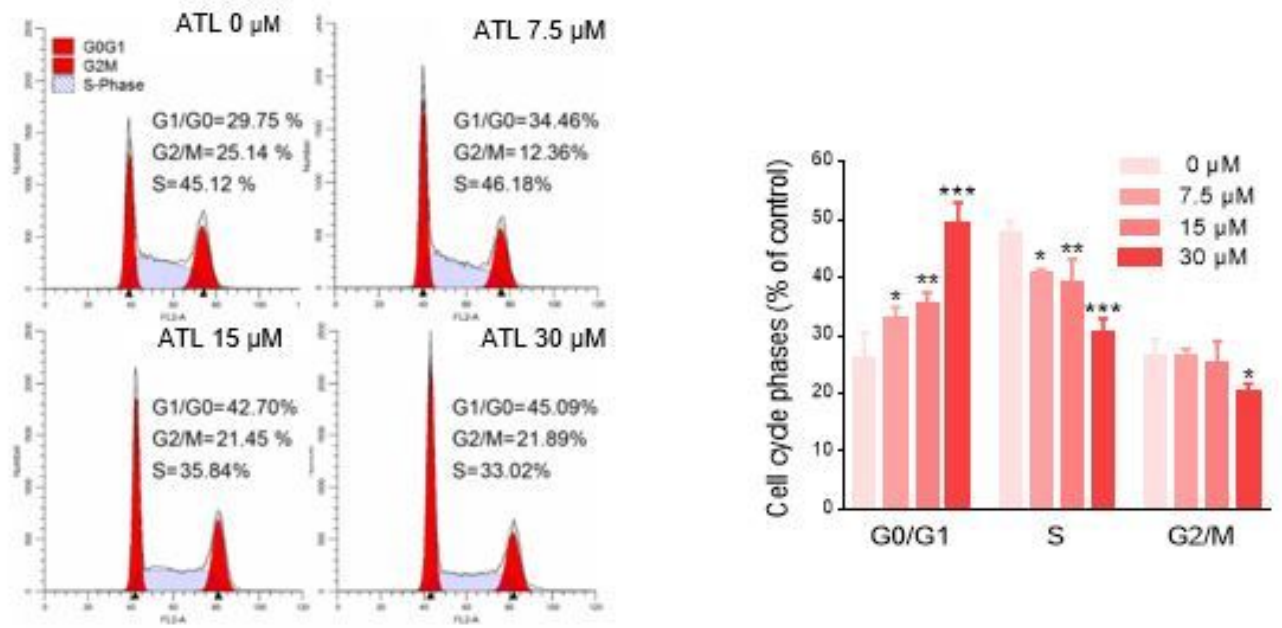

B
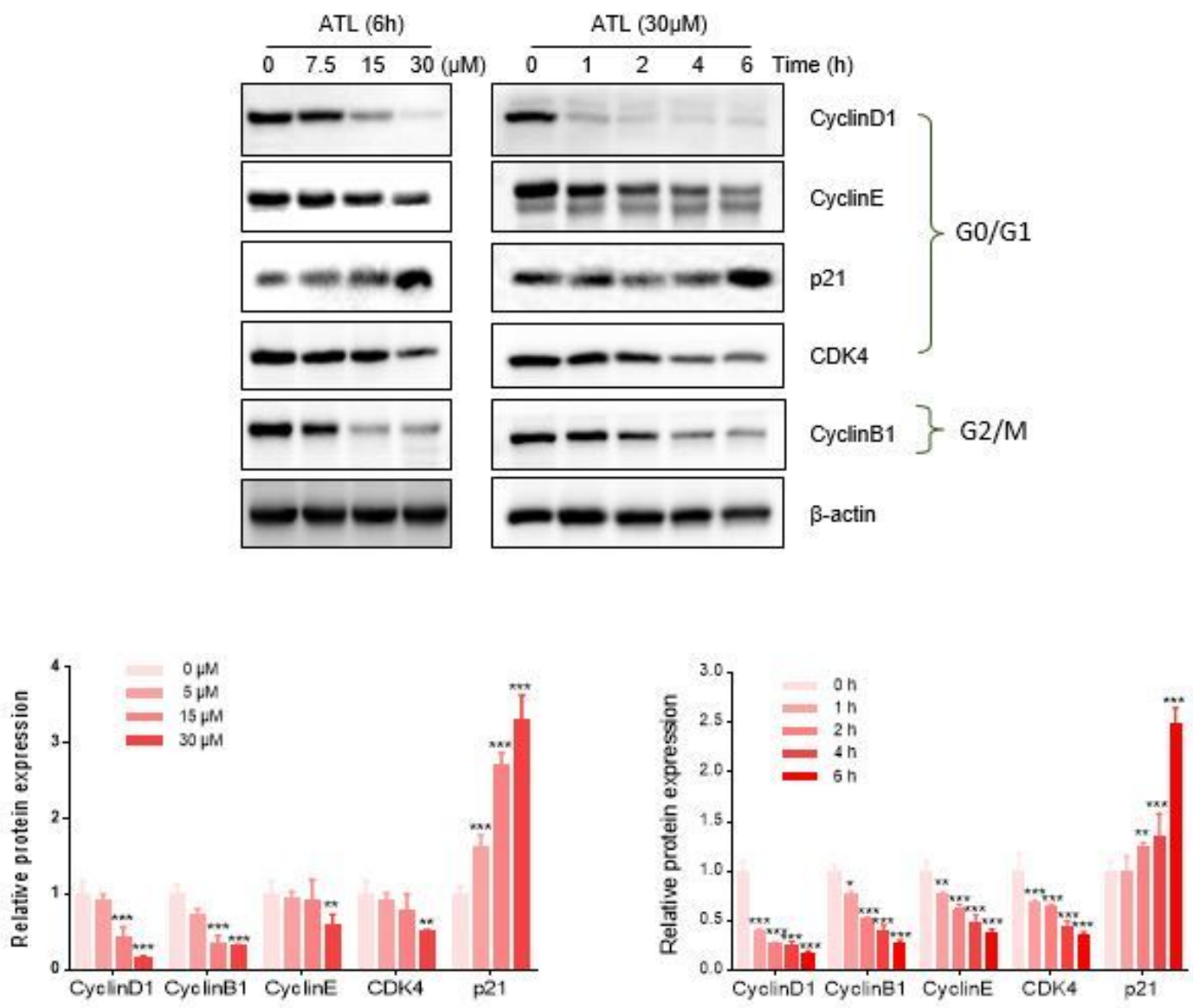

\section{Figure 3}

ATL induced G0/G1 phase arrest in HCT116 cells. (A) The cell cycle distribution of Control and ATLtreated $(7.5,15$, or $30 \mu \mathrm{M})$ cells was assessed by flow cytometry. Statistical analysis of the cell cycle distribution for all cells after three independent replicates. (B) HCT116 cells were treated with ATL $(7.5,15$, or $30 \mu \mathrm{M})$ for $6 \mathrm{~h}$ or treated with ATL $(30 \mu \mathrm{M})$ for $1,2,4$, or $6 \mathrm{~h}$. The protein expression of cyclin-D1, cyclinB1, cyclin-E, CDK4, p21, and $\beta$-actin in HCT116 cells was determined by immunoblotting. Protein 
expression was normalized to that of $\beta$-actin. Data are presented as means $\pm S D(n=3) .{ }^{* *} p<0.01,{ }^{* \star *} p<$ 0.001 vs. the $0-\mu \mathrm{M}$ group.

A

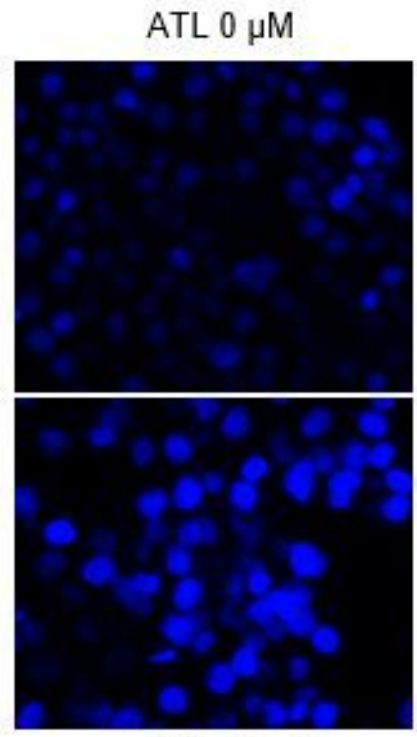

ATL $15 \mu \mathrm{M}$
ATL $7.5 \mu \mathrm{M}$

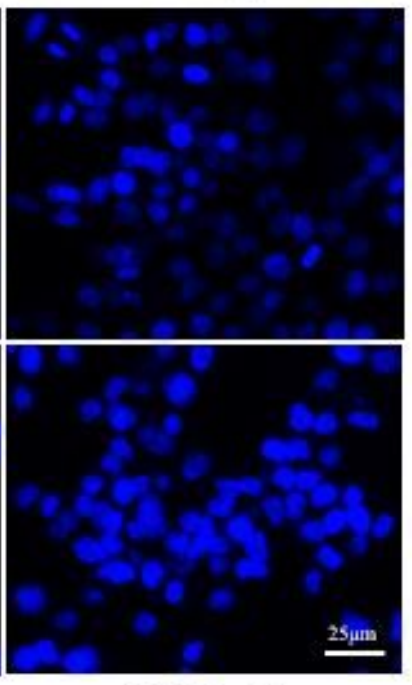

ATL $30 \mu \mathrm{M}$

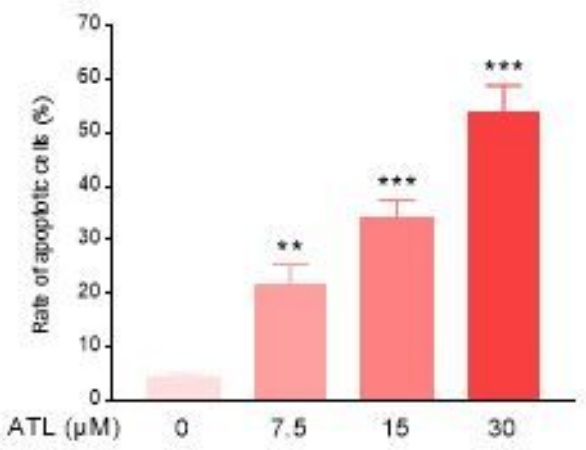

B
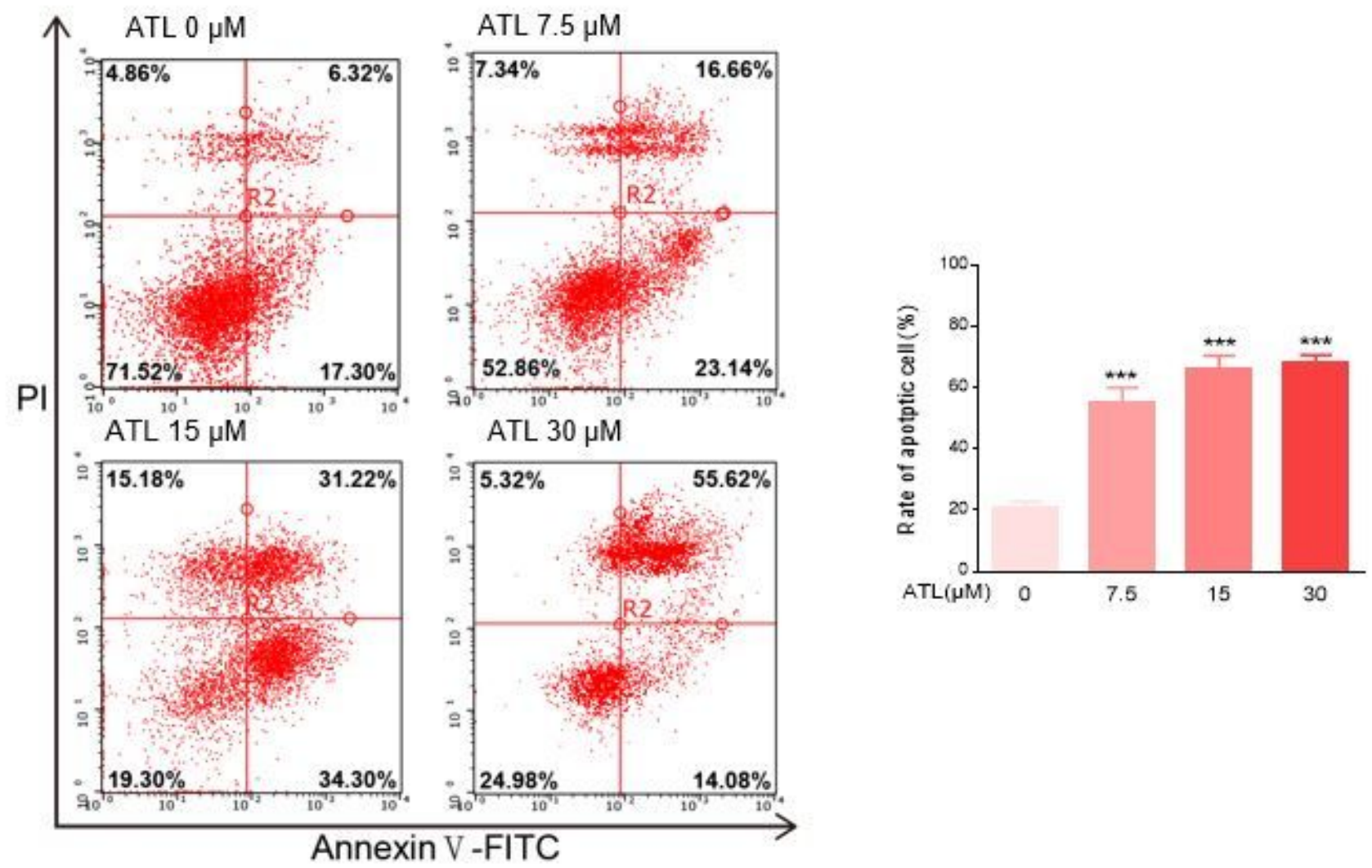

Figure 4

ATL induced cell apoptosis in HCT116 cells. (A) Hoechst staining was performed to detect the occurrence of apoptosis in HCT116 cells treated with $\operatorname{ATL}(7.5,15$, or $30 \mu \mathrm{M})$ for $24 \mathrm{~h}$. Three visual fields were randomly selected for the evaluation of apoptotic rates. Scale bar $=25 \mu \mathrm{m}$. (B) The apoptosis of HCT116 
cells was detected by flow cytometry with annexin V-FITC/PI double staining, and the experiment was repeated three times. Statistical analysis of apoptotic cells. Data are presented as means $\pm S D(n=3) .{ }^{* *} p$ $<0.01$, *** $\mathrm{p}<0.001$ vs. the $0-\mu \mathrm{M}$ group.

\section{A}
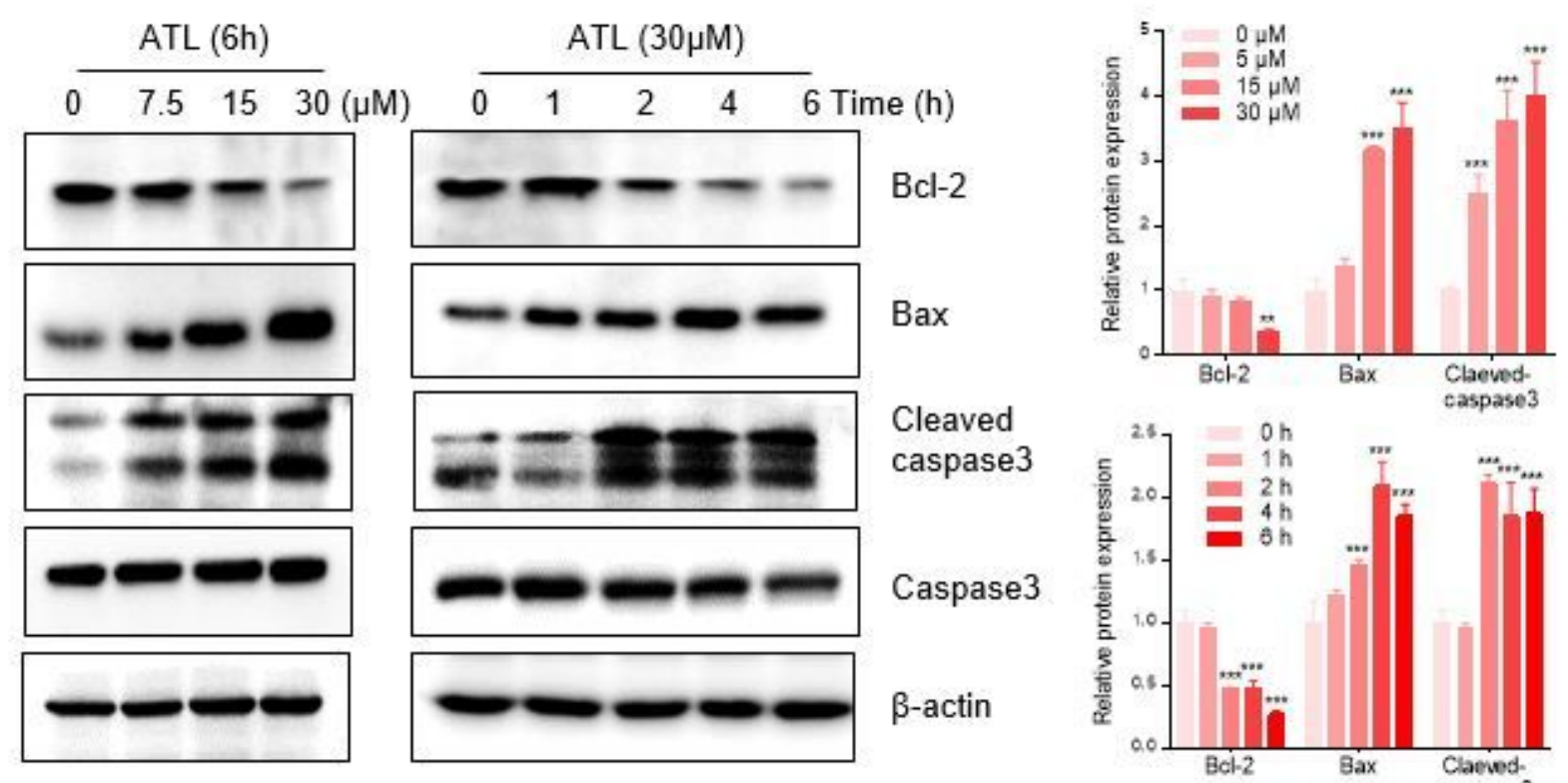

$\mathrm{Bcl}-2$

Bax

Caspase 3

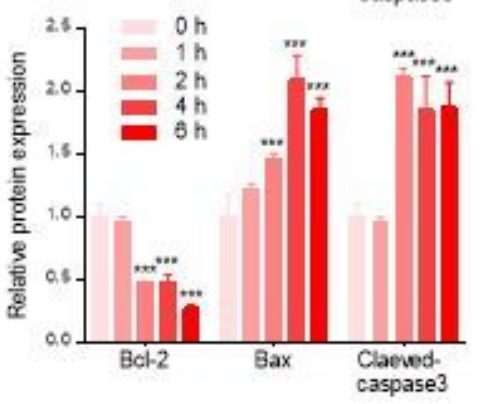

B

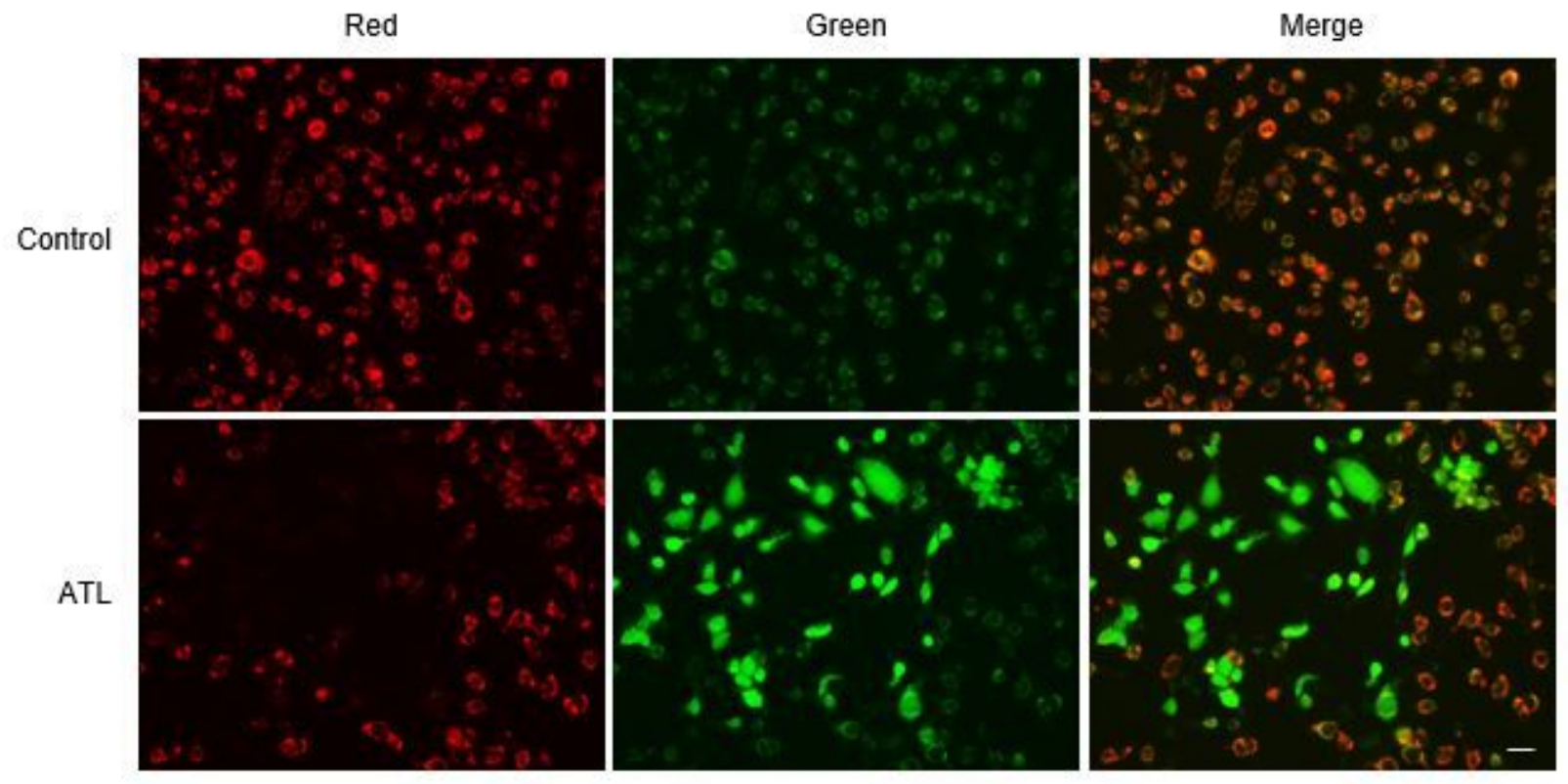

Figure 5

ATL induced apoptosis through the exogenous channels in HCT116 cells. (A) HCT116 cells were treated with $\operatorname{ATL}(7.5,15$, or $30 \mu \mathrm{M})$ for $6 \mathrm{~h}$ or treated with ATL $(30 \mu \mathrm{M})$ for $1,2,4$, or $6 \mathrm{~h}$. The protein expression 
of $\mathrm{Bcl}-2$, BAX, cleaved caspase-3, caspase-3, and $\beta$-actin in HCT116 cells was determined by immunoblotting. Protein expression was normalized to that of $\beta$-actin. (B) JC-1 staining of cells treated with ATL $(30 \mu \mathrm{M})$ for the indicated times was observed by fluorescence microscopy. Scale bar $=25 \mu \mathrm{m}$. Data are presented as means $\pm S D(n=3) .{ }^{*} p<<0.05$, $* \star * p<0.001$ vs. the $0-\mu M$ group.

A
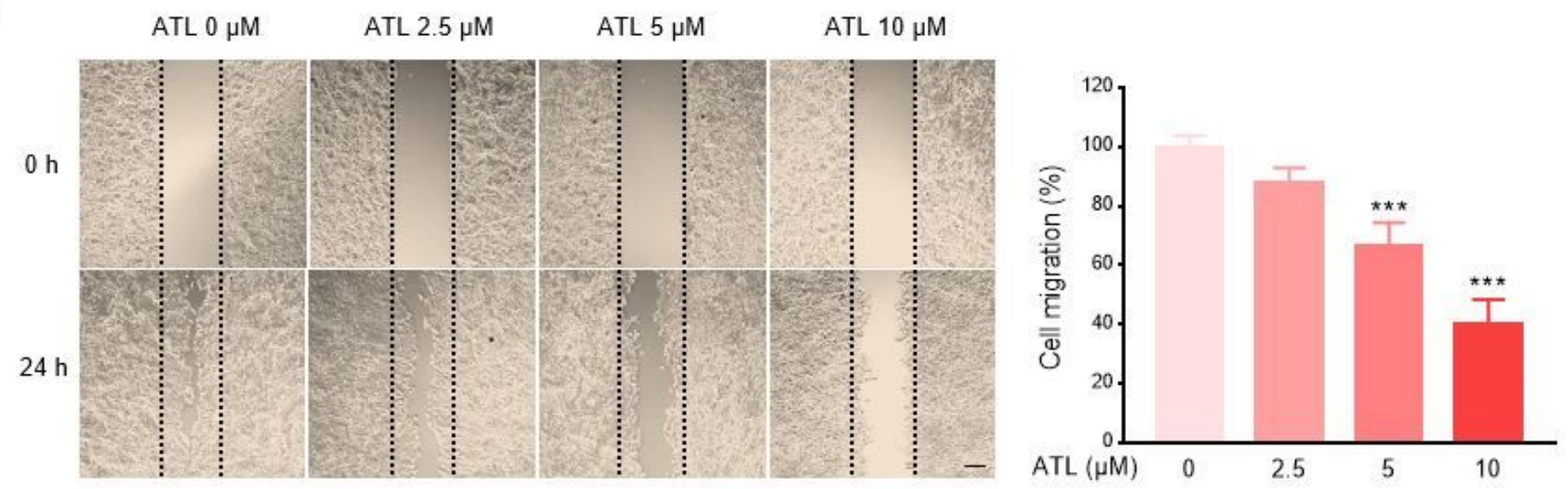

B
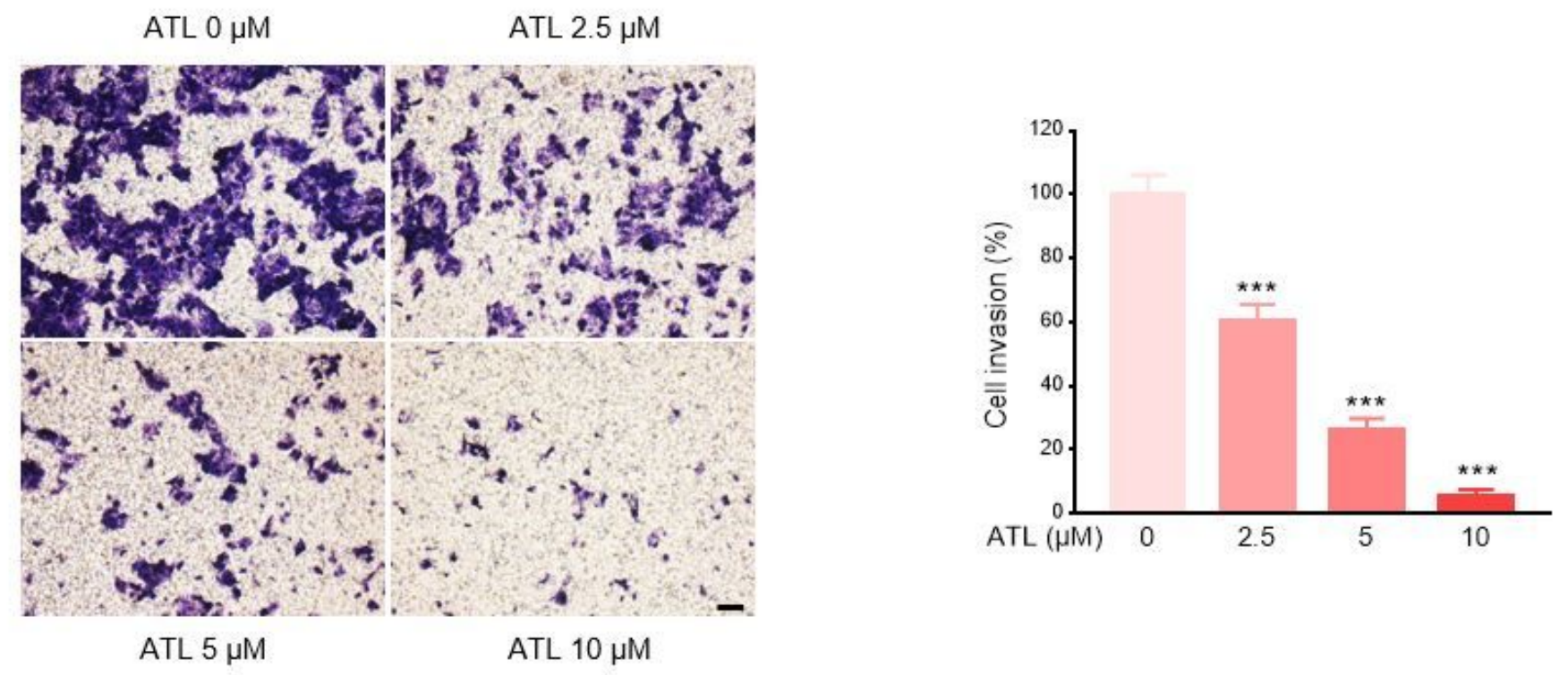

Figure 6

ATL inhibited the invasive and migratory abilities of HCT116 cells. (A) The migration of HCT116 cells after treatment with ATL $(2.5,5$, or $10 \mu \mathrm{M})$ was detected by wound-healing assay. The relative migrated distances were measured three times for each scratch. (B) HCT116 cells were pretreated with ATL $(2.5,5$, or $10 \mu \mathrm{M})$ for $24 \mathrm{~h}$ and then seeded in Transwell chambers. Serum-containing medium was added for 24 $\mathrm{h}$ to induce cell invasion. After $24 \mathrm{~h}$, noninvading cells were removed from inside the chamber, and migrated cells were fixed, stained, and counted. The OD value of the crystal violet eluent was measured at 
$595 \mathrm{~nm}$, and this was repeated three times. Scale bar $=100 \mu \mathrm{m}$. Data are presented as means $\pm S D(n=3)$. ${ }^{* *} \mathrm{p}<0.05,{ }^{* \star *} \mathrm{p}<0.001$ vs. the $0-\mu \mathrm{M}$ group.

A
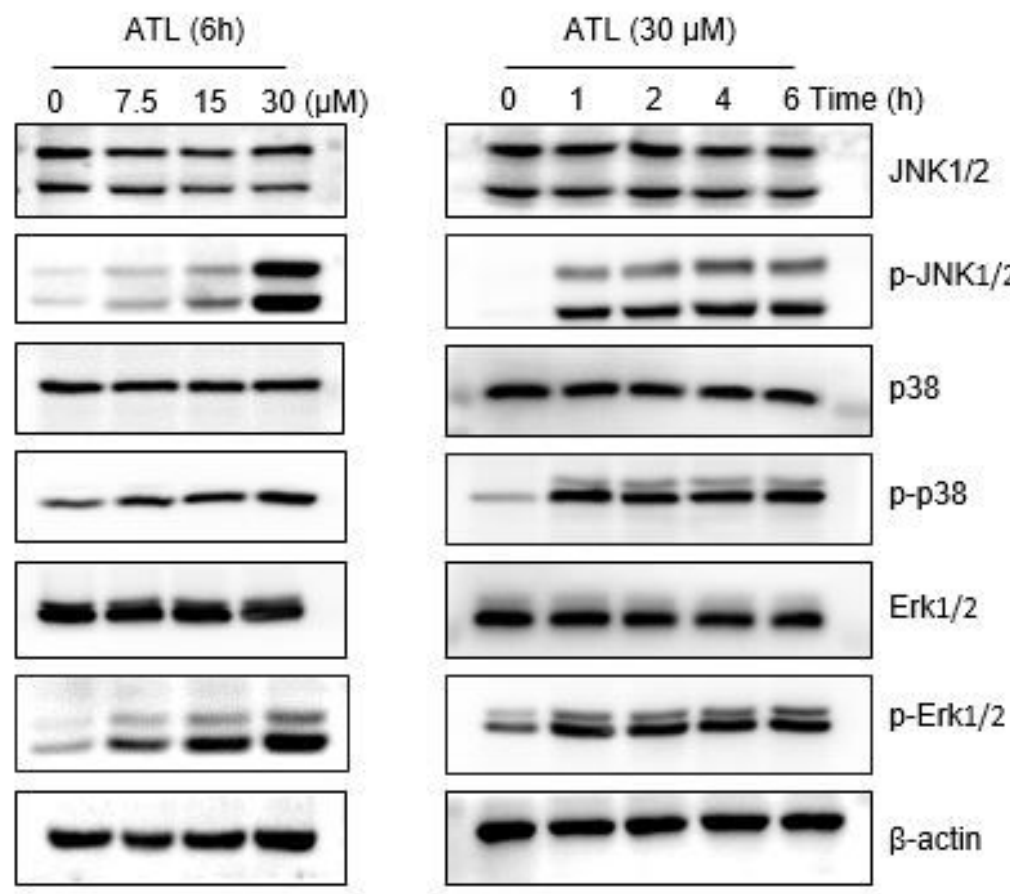

B
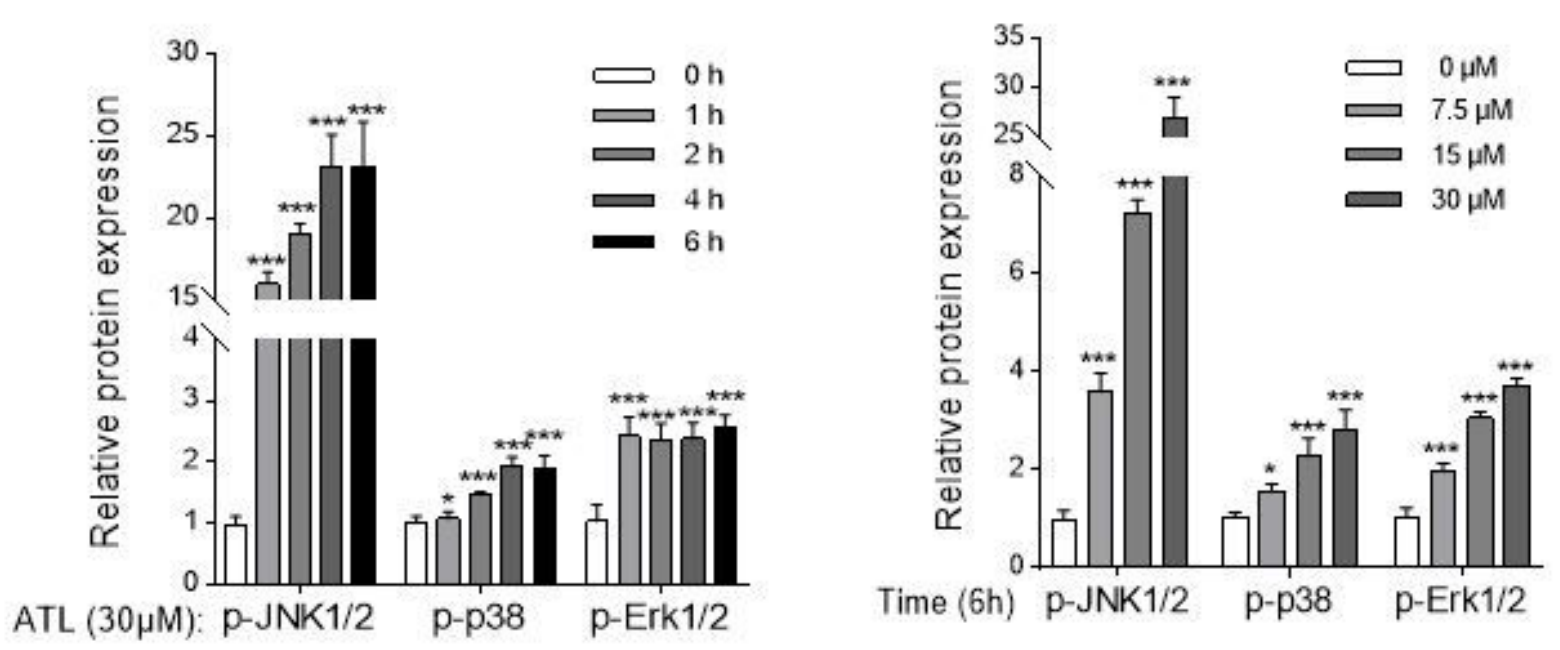

Figure 7

ATL activated the MAPK-JNK/c-Jun signaling pathway in HCT116 cells. (A, B) HCT116 cells were treated with ATL $(7.5,15$, or $30 \mu \mathrm{M})$ for 6 h or treated with ATL $(30 \mu \mathrm{M})$ for $1,2,4$, or $6 \mathrm{~h}$. The protein expression 
of JNK1/2, p-JNK1/2, p38, p-p38, ERK1/2, p-ERK1/2, and $\beta$-actin in HCT116 cells was determined by immunoblotting. Data are presented as means $\pm S D(n=3) .{ }^{*} p<0.05,{ }^{* \star *} p<0.001$ vs. the $0-\mu M$ group.

A
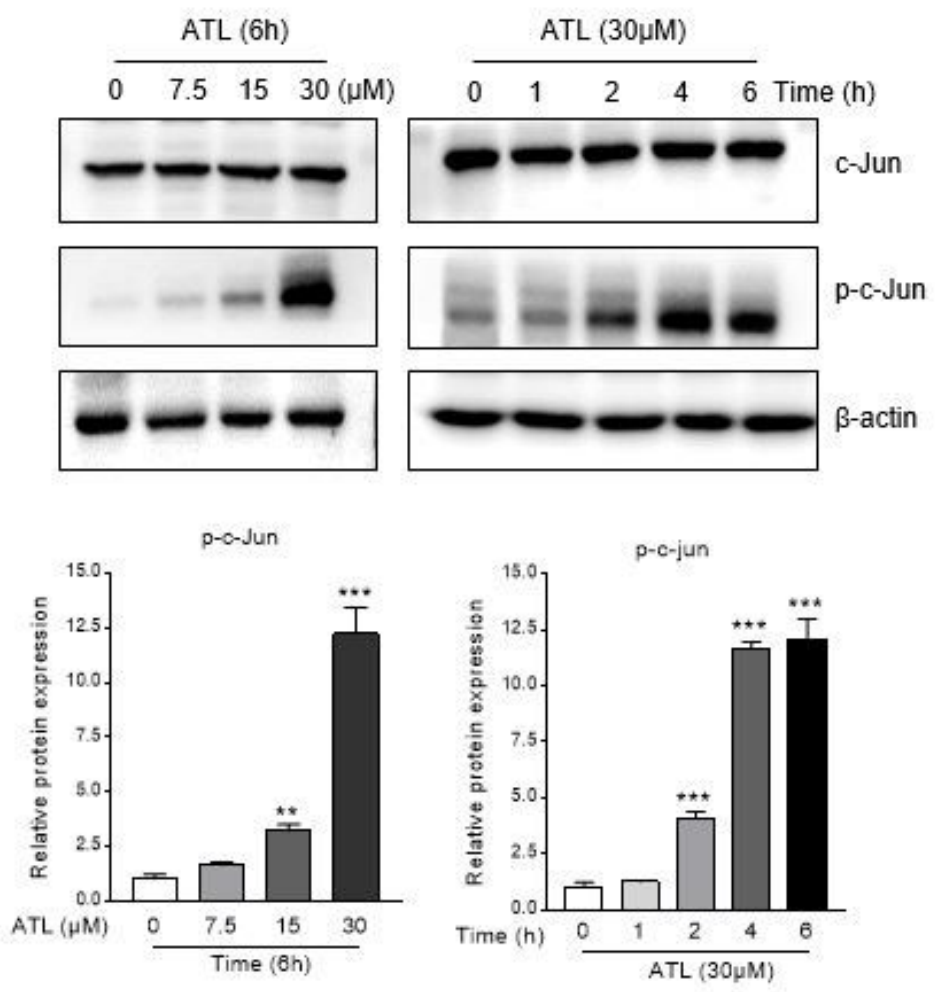

B

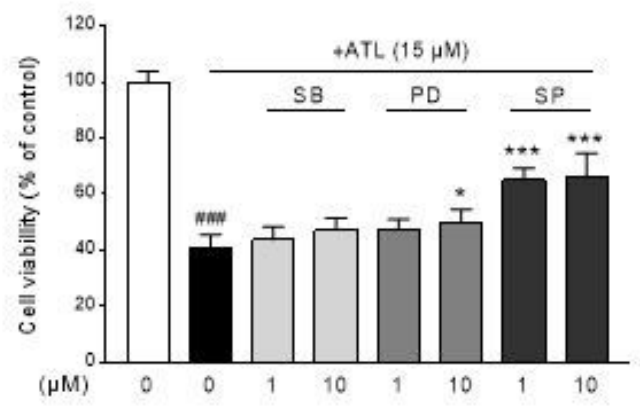

C
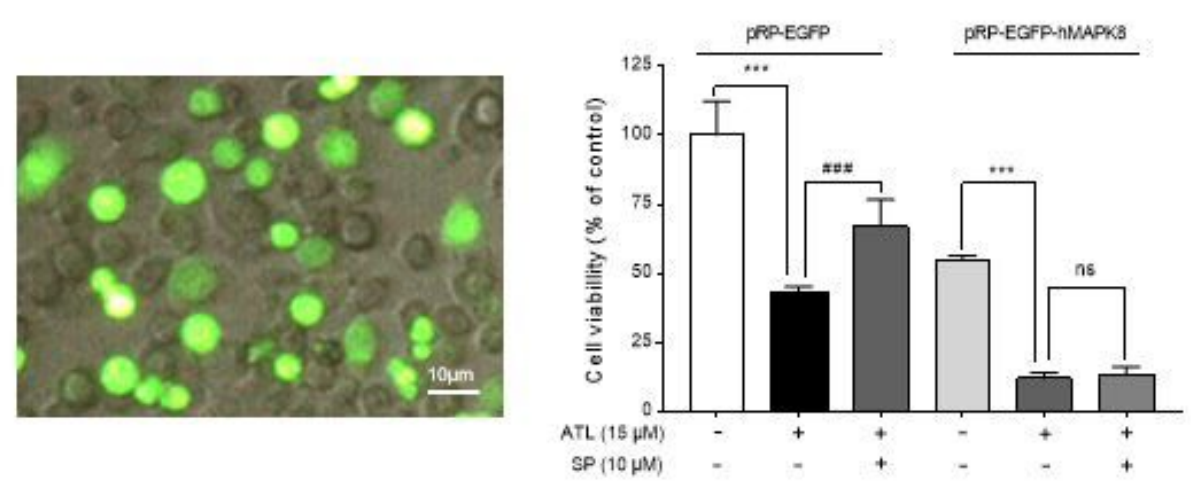

Figure 8

ATL activated the MAPK-JNK/c-Jun signaling pathway in HCT116 cells. (A) HCT116 cells were treated with ATL $(7.5,15$, or $30 \mu \mathrm{M})$ for $6 \mathrm{~h}$ or treated with ATL $(30 \mu \mathrm{M})$ for $1,2,4$, or $6 \mathrm{~h}$. The protein expression of c-Jun, p-c-Jun, and $\beta$-actin in HCT116 cells was determined by immunoblotting. Protein expression 
was normalized to that of $\beta$-actin. Data are presented as means $\pm S D(n=3)$. (B) HCT116 cells were pretreated with various MAPK inhibitors $(1$ or $10 \mu \mathrm{M})$ for $2 \mathrm{~h}$ before ATL treatment $(15 \mu \mathrm{M})$, and then cell viability was measured. SP (SP600125), a JNK inhibitor; SB (SB203580), a p38 inhibitor; PD (PD98059), an ERK inhibitor. (C) The pRP-EGFP-hMAPK8 plasmid was transfected into HCT116 cells by electric transfection (the left side). Then HCT116 cells were pretreated with JNK inhibitor $(10 \mu \mathrm{M})$ for $2 \mathrm{~h}$ before ATL treatment $(15 \mu \mathrm{M})$, and then cell viability was measured (the right side). Data are presented as means $\pm S D(n=6)$. \#\#\#p<0.001 vs. the $0-\mu M$ group; ${ }^{*} p<0.05$, *** $p<0.001$ vs. the ATL $(15 \mu M)$ group.

A

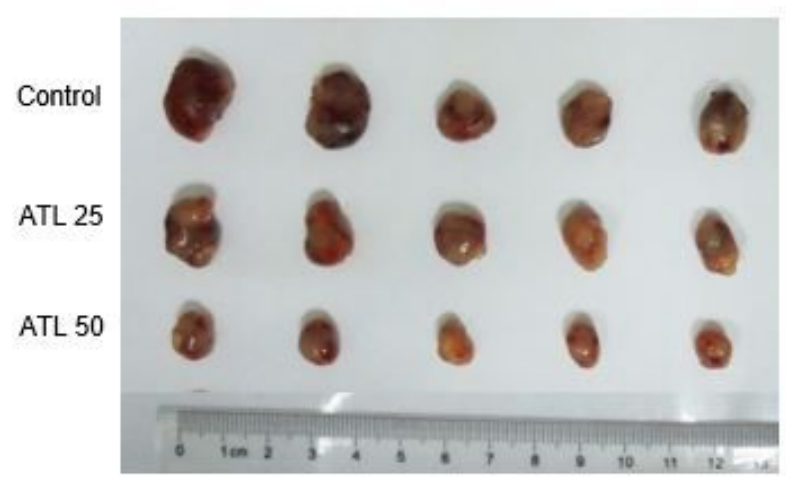

C

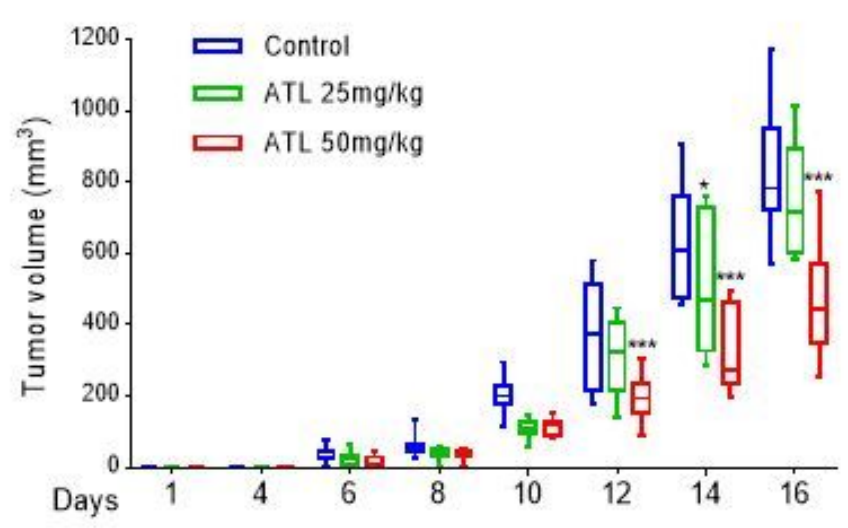

B
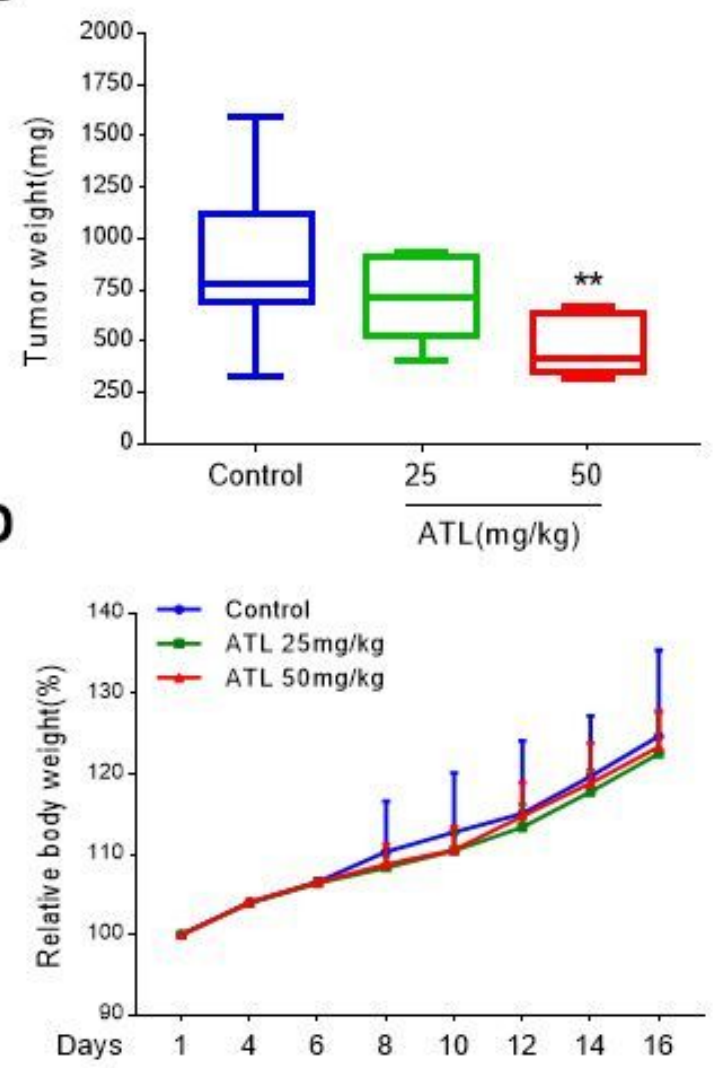

\section{Figure 9}

ATL inhibited tumor growth in colon cancer xenograft model. (A) ATL (50 mg/kg) significantly inhibited tumor growth. (B) Tumor weight were measured after the sacrifice of animal. (C) Tumor volume were measured during the test period. (D) The mice body weight changes were monitored throughout the study. Data are presented as means $\pm S D(n=5) .{ }^{*} p<0.05,{ }^{* \star} p<0.01,{ }^{* \star} p<0.001$ vs. the Control group. 
A

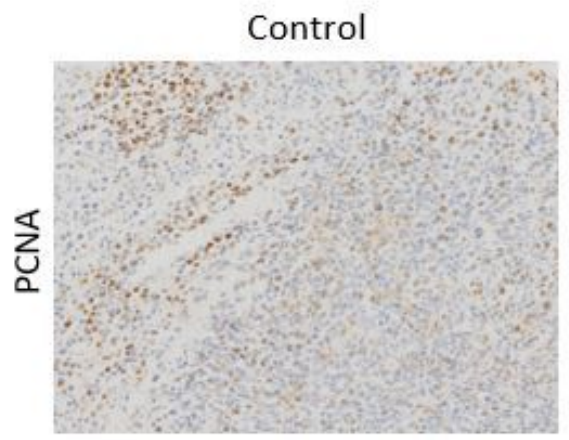

C

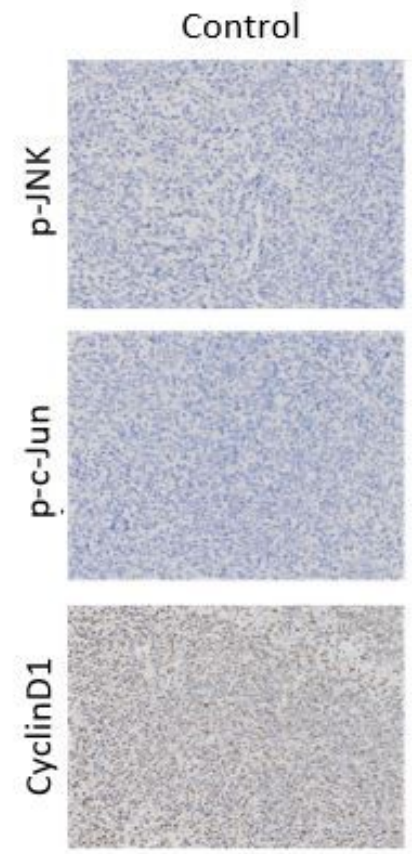

ATL $50 \mathrm{mg} / \mathrm{kg}$

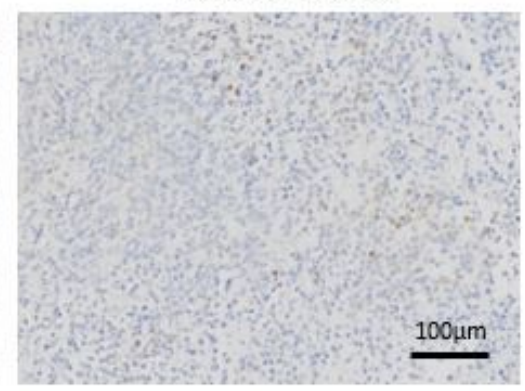

D

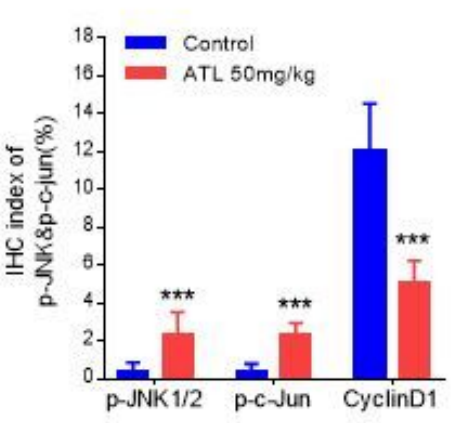

$\mathbf{F}$

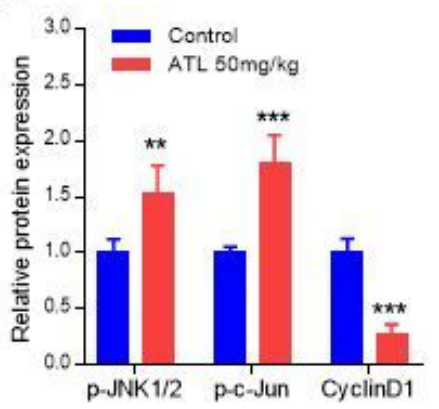

B

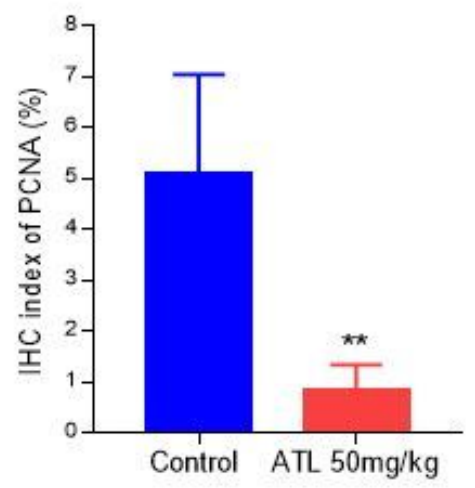

$\mathbf{E}$
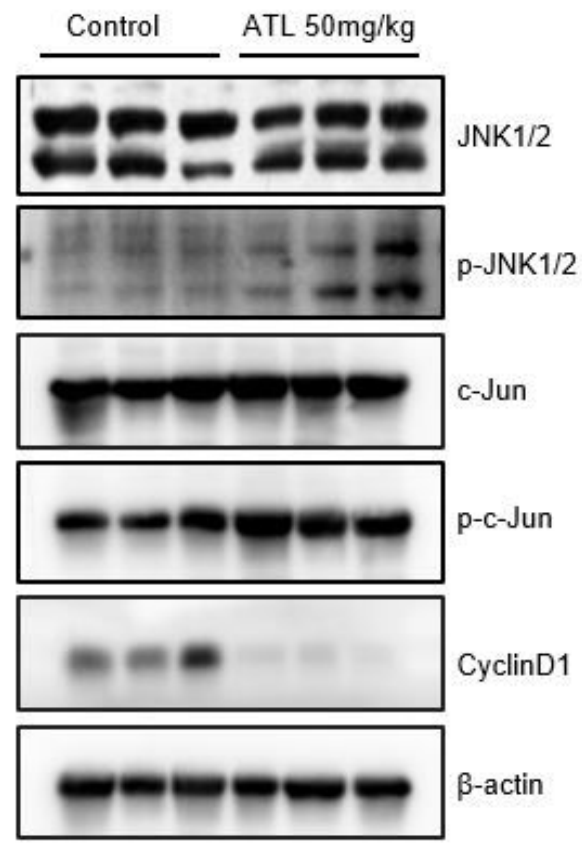

\section{Figure 10}

ATL treatment inhibited colon tumor growth via activating MAPK-JNK/C-Jun signal pathway. (A) Expression of PCNA (brown) in the tumor tissues, as determined by immunohistochemistry. (B) Quantification of expression levels of PCNA in tumor tissue is shown. (C) Expression of p-JNK, p-C-Jun and CyclinD1 (brown) in the tumor tissues, as determined by immunohistochemistry. (D) Quantification of expression levels of p-JNK, p-C-Jun and CyclinD1 in tumor tissue is shown. (E and F) Protein levels of JNK1/2, p-JNK1/2, c-Jun, p-c-Jun, CyclinD1 were measured via western bloting. All the expressions were normalized to $\beta$-actin. ${ }^{*} p<0.05,{ }^{*} p<0.01,{ }^{* \star} p<0.001$ vs. the Control group. 


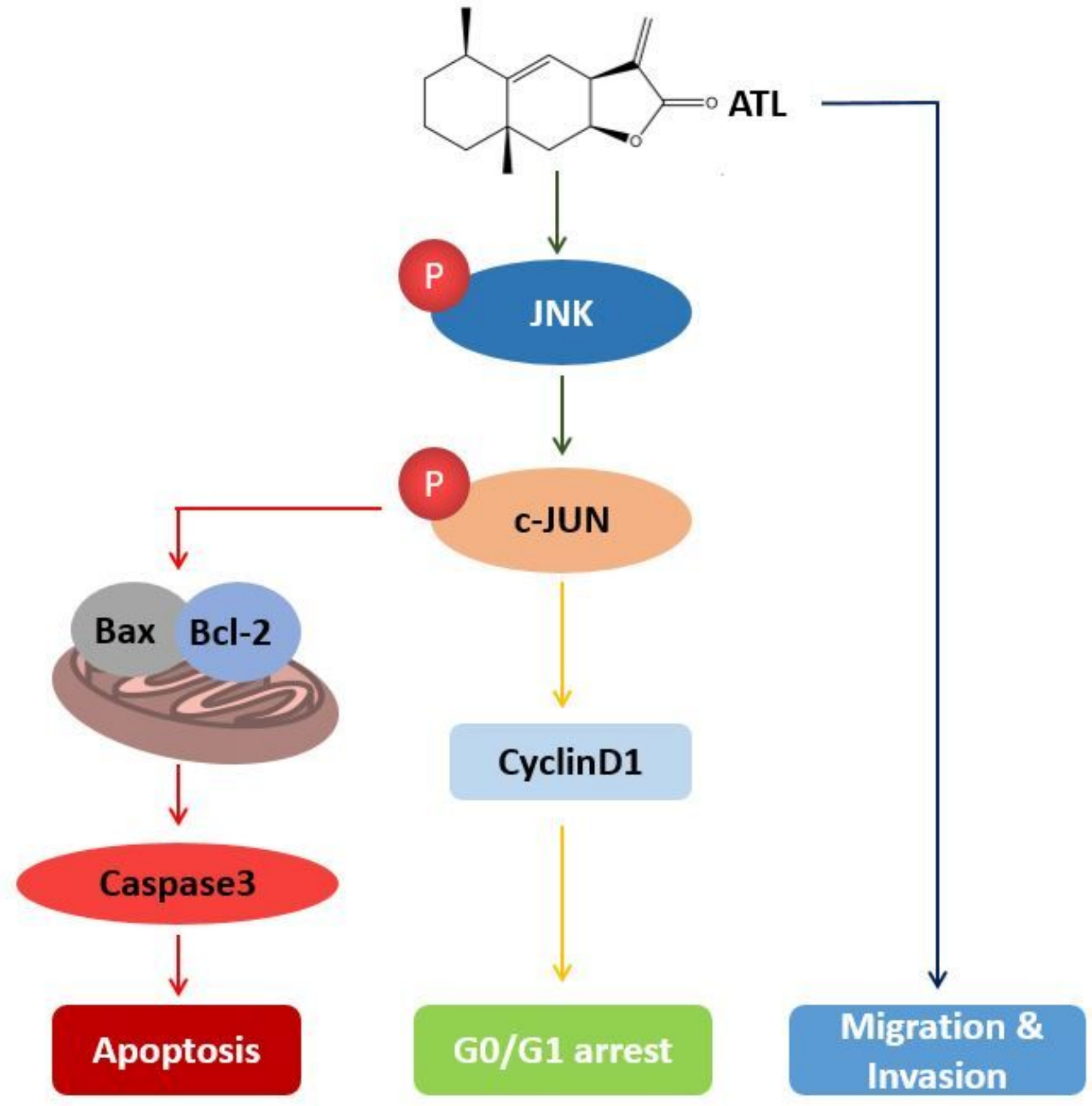

\section{Figure 11}

The antitumor mechanism of ATL in colon cancer model. ATL may exert its anticolorectal cancer effects by activating the MAPK-JNK/C-Jun signaling pathway, inducing G0/G1 phase arrest, and activating the mitochondrial-mediated apoptotic pathway. 